\title{
Theory of mind and joint action in Parkinson's disease
}

\author{
Marco Fabbri ${ }^{1}$ (D) Carmine Vitale $^{2,3} \cdot$ Sofia Cuoco $^{4}$ - Alessia Beracci ${ }^{1} \cdot$ Rosanna Calabrese $^{1} \cdot$ Maria Cordella $^{1}$. \\ Regina Mazzotta ${ }^{1}$ - Paolo Barone ${ }^{4} \cdot$ Maria Teresa Pellecchia $^{4} \cdot$ Gabriella Santangelo $^{1,3}$
}

Published online: 26 September 2018

(C) Psychonomic Society, Inc. 2018

\begin{abstract}
It has been suggested that the Theory of Mind (ToM) may rely on more basic processes of social cognition, such as action control (e.g., joint action), even if little is known about this relationship. The relationship between ToM and joint action can be studied in patients with Parkinson's disease (PD), because they are characterized not only by a deficit in ToM (and in its cognitive and affective subcomponents) but also by a deficit in the inhibition of competing responses. Sixty PD patients and 60 matched healthy controls (HCs) performed a go/no-go Flanker task in both joint and individual conditions. Cognitive (Advanced Test or AT) and affective (Emotion Attribution Task or EAT) ToM also were measured. Thirty-five PD patients and matched HCs also performed the standard Flanker task, as a control measure. In patients, only individuals with high AT scores exhibited a joint Flanker effect, whereas in HCs the joint effect was found irrespectively of AT score. Patients with low EAT scores showed a greater interference effect than patients with high scores, whereas the opposite pattern was found for HCs. In regression analysis AT and EAT scores predicted the Flanker effect in the joint condition only. In the standard task, both groups showed a Flanker effect. The role of different fronto-striatal circuits, especially in PD patients, could explain the different involvement of cognitive and affective ToM in joint tasks. The Flanker effect is discussed considering the referential coding account and the attention-focus account as possible candidates to explain joint action effects.
\end{abstract}

Keywords Theory of Mind · Joint action $\cdot$ Parkinson's disease $\cdot$ Flanker effect $\cdot$ Social cognition

\section{Introduction}

Parkinson's disease (PD) is a progressive neurodegenerative disorder of the motor system that is due to a selective loss of dopaminergic neurons in the substantia nigra and ventral tegmental areas. In addition to motor impairment (Obeso, Rodriguez-Oroz, Rodriguez, et al., 2000), recent studies show

Electronic supplementary material The online version of this article (https://doi.org/10.3758/s13415-018-0642-0) contains supplementary material, which is available to authorized users.

Marco Fabbri

marco.fabbri@unicampania.it

1 Department of Psychology, University of Campania "Luigi Vanvitelli”, Viale Ellittico, 31, 81100 Caserta, Italy

2 Department of Motor Sciences and Wellness, University "Parthenope", Naples, Italy

3 Institute of Diagnosis and Care (IDC), Hermitage-Capodimonte, Naples, Italy

4 Neurodegenerative Diseases Center, University of Salerno, Salerno, Italy that $\mathrm{PD}$ is characterized by a deficit in social cognitive abilities (Kawamura \& Koyama, 2007) and specifically by an impairment in Theory of Mind (ToM), starting from the early stages of the disease (Bodden, Dodel, \& Kalbe, 2010a; Bodden, Mollenhauer, Trenkwalder, et al., 2010b; Freedman \& Stuss, 2011; Mengelberg \& Siegert, 2003; Poletti, Enrici, Bonuccelli, \& Adenzato, 2011; Saltzman, Strauss, Hunter, \& Archibald, 2000; Santangelo, Vitale, Trojano et al., 2012; Yu $\& \mathrm{Wu}, 2013)$. Theory of Mind refers to the ability to represent one's own and another's mental states, such as intentions, beliefs, desires, and knowledge (Baron-Cohen, Leslie, \& Frith, 1985; Frith \& Frith, 1999; Premack \& Woodruff, 1978). For instance, Saltzman et al. (2000) found that PD patients were less able to make correct predictions based on inferences regarding a story-character's belief (Mengelber \& Siegert, 2003, for deficits in false beliefs shown by PD patients). It is worth noting that ToM has been suggested to have two subcomponents: cognitive and affective (Kalbe, Schlegel, Sack, et al., 2010; Shamay-Tsoory, Harari, Aharon-Peretz, \& Levkovitz, 2010; Shamay-Tsoory, Shur, Barcai-Goodman, Medlovich, Harari, \& Levkovitz, 2007). The first component regards cognitive understanding of the difference between the knowledge of the speaker and that of 
the listener (knowledge about beliefs), whereas the second component regards the empathic appreciation of the listener's emotional state (knowledge about emotions). These two components can be dissociated and impaired independently from each other (Péron, Vicente, Leray, et al., 2009; ShamayTsoory et al., 2007). Although this dissociation has not been systematically confirmed (Bodden et al., 2010a, b; Kalbe et al., 2010; Poletti et al., 2011; Santangelo et al., 2012; Shamay-Tsoory \& Aharon-Peretz, 2007), some studies, using various tasks, have found that PD patients have impaired cognitive ToM (Bodden et al., 2010a, b; Costa, Peppe, Martini, et al., 2013; Mengelberg \& Siegert, 2003; Monetta, Grindrod, \& Pell, 2009; Péron, et al., 2009; Roca, Torralva, Gleichgerrcht, et al., 2010; Santangelo et al., 2012), suggesting that PD patients have more difficulty recognizing why a person in the story made an inappropriate remark.

The impairments in fronto-striatal circuities also can lead to cognitive impairments (Goldman \& Litvan, 2011; Owen, 2004; Zgaljardic, Borod, Foldi, et al., 2006), affecting multiple domains (but see Williams-Gray, Evans, Goris, et al., 2009 , for a heterogeneous profile), including frontal and executive functions (such as updating and working memory abilities). Costa et al. (2013) showed a causal relationship between an altered functioning of cognitive ToM and executive deficits. The authors divided PD patients into two groups according to their performance in an executive test: a group of dysexecutive patients, who had performed poorly, and an executively unimpaired group. Faux pas recognition written stories were administered to both groups, as well as to matched healthy controls (HCs). Only dysexecutive PD patients performed less accurately than executively unimpaired PD patients and HCs on all faux pas stories, whereas no differences between executively unimpaired patients and HCs were found in the ToM task. These data showed that ToM impairment of $\mathrm{PD}$ patients was a function of executive impairment, indirectly confirming the role of prefrontal regions in mediating ToM abilities. However, the faux pas task does not differentiate between cognitive and affective aspects of ToM (Shamay-Tsoory \& Aharon-Peretz, 2007), raising the question of whether the difficulty exhibited by dysexecutive PD patients in the ToM task was related to their failure to process purely cognitive or affective aspects of the task, or both. To resolve this limitation, in the present study we used the Italian version of the Advanced Test of ToM (AT; Prior, Marchi, \& Sartori, 2003) for cognitive ToM and the modified Italian version of the Emotion Attribution Task (EAT; Prior et al., 2003) for affective ToM.

The involvement of the frontal lobe in modulating ToM abilities has also been shown by Humphreys and Bedford (2011), who investigated the relationship between ToM and joint action, especially in neuropsychological patients. Joint action, a concept within social cognitive neuroscience that refers to the ability to coordinate one's own action with that of others to achieve a common goal, requires the representations of the common goal and of the other's actions in relation to that goal. A convincing paradigm with which to study joint action was developed by Sebanz, Knoblich, and Prinz (2003), starting from the classical Simon effect (Simon, 1969). When participants have to press two lateralized keys to detect a specific feature of a spatially presented target, the Simon effect (Simon, 1969, 1990) indicates a spatial compatibility effect, suggesting that the spatial position of the target influences the reaction times (RTs) when there is a correspondence between the spatial position of the target and that of the lateralized key, even if this spatial correspondence is irrelevant for the task. It is widely confirmed that the spatial compatibility effect occurs due to a conflict at the response selection stage (De Jong, Liang, \& Lauber, 1994). According to the dimensional overlap model (Kornblum, Hasbroucq, \& Osman, 1990), the conflict is caused by an overlap between the spatial stimulus and the response (left-right) dimension, determining a facilitation (or interference) when there is compatibility (or incompatibility) between spatial feature of the stimulus and spatially corresponding response. Related to this point, the Simon effect disappears when participants perform a go/no-go version of the task, carrying out a single keypress response. However, Sebanz et al. (2003) found a spatial compatibility effect (joint Simon effect) when two co-actors performed a Simon task, each providing a go/no-go response to a single feature of the target. Crucially, the joint Simon effect was not found when participants performed the task alone (without the co-actor) in the individual go/no-go condition. These findings indicate that, when two individuals jointly perform a task, they represent not only their own part of the task, but also the part to be performed by the co-actor, suggesting a co-representation of the task. When applying this joint paradigm to patients with posterior parietal cortex (PPC) and temporo-parietal junction (TPJ) lesions as well as to patients with frontal lesions, Humphreys and Bedford (2011) found that PPC/TPJ patients preserved the basic ability to represent the mental state of another person, showing a joint action effect when explicitly instructed to attend to the co-actor, while the frontal patients not only failed on the ToM task but also failed to show any joint action effect, even when the partner's behaviour was highlighted.

However, the action co-representation account for the joint compatibility effect has recently been challenged (Dittrich, Bossert, Rothe-Wulf, \& Klauer, 2017; Dittrich, Dolk, RotheWulf, et al., 2013; Dittrich, Rothe, \& Klauer, 2012; Dolk, Hommel, Prinz, \& Liepelt, 2013, 2014a; Doneva \& Cole, 2014; Guagnano, Rusconi, \& Umiltà, 2010; Hommel, Colzato, \& van den Wildenberg, 2009; Klempova \& Liepelt, 2015; Liepelt, Wenke, Fischer, \& Prinz, 2011; Müller, Brass, Kühn, et al., 2011a; Porcu, Bölling, Lappe, \& Liepelt, 2016; Puffe, Dittrich, \& Klauer, 2017; Sellaro, Dolk, Colzato, et al., 2015; Stenzel \& Liepelt, 2016; see Dolk, Hommel, Colzato 
et al., 2011, 2014b for reviews). One of these recent alternative accounts is the referential coding account (Dolk et al., 2011, 2013, 2014a,b), which offers a plausible explanation for modulations of the joint Simon effect in a number of observations, such as group membership (i.e., in-group vs. out-group; Müller, Kühn, van Baaren et al., 2011b) or the presence of a joint Simon effect in presence of nonhuman co-actors (e.g., Japanese waving cat: Dolk et al., 2013) compared with the action co-representation account. Specifically, it has been assumed that participants represent their own response to taskrelevant stimuli just like other events, as predicted by the Theory of Event Coding (TEC; Hommel, 2009, 2011; Hommel, Müsseler, Aschersleben, \& Prinz, 2001). According to TEC, the event codes are organized in a specific way (Hommel et al., 2001). When the task is shared between two actors, both internal (self-) and external (other-generated) events are cognitively represented in a common coding format. However, this common coding determines a discrimination problem in a joint go/no-go (Simon) task, due to the activation of internal and external action events. According to TEC, the more the features are shared by different events (i.e., greater similarity between different events determines greater overlapping between their representations; see Prinz, 2015 for an overview), the more they can be related to each other. In joint go/no-go tasks, both self- and other-events are highly similar because they require simple button pressing. In other words, the cognitive representation of self- and otherevents induces a response-selection conflict between self-own action and other-own action when a given stimulus is presented (Liepelt, et al., 2011; Liepelt, Wenke, \& Fischer, 2013). In this situation, the discrimination problem is solved by emphasizing response features that clearly discriminate between actions in a given task context, thus increasing the weight of feature codes (i.e., intentional weighting; Memelink \& Hommel, 2013) in the internal representation of actions. For instance, in the Simon task, the discriminating feature is the spatial (left-right) response location and thus actions are coded more strongly (i.e., response location is weighted more strongly; Hommel et al., 2009) in terms of left and right (referential coding) in the presence of another responding human or nonhuman co-actor, determining a larger joint Simon effect compared to the situation in which another human/nonhuman co-actor is absent. According to the referential coding account, any event sharing a discriminating feature, such as spatial presentation of stimuli, activates the corresponding (response) action more strongly due to a higher dimensional overlap (Kornblum et al., 1990) between spatial stimulus and response dimension. Therefore, the dimensional overlap is higher in the joint than in the individual condition, also because in this latter situation the referential coding is unnecessary due to the absence of an alternative event (i.e., the absence of a co-actor).

Interestingly, the joint action effect has been found in healthy participants using other types of stimulus-response mapping and interference tasks, such as the Flanker task (Atmaca, Sebanz, \& Knoblich, 2011; Peterburs, Liepelt, Voegler, et al., 2017); this suggests how the Flanker paradigm is a promising candidate for further scrutinizing joint action, considering that the (Eriksen) Flanker task incorporates response conflict as does the Simon task, and that in this task the interference arises from short-lived stimulus-response assignments that are arbitrary and categorical (and not based on spatial features). In its standard version of the task (as created by Eriksen \& Eriksen, 1974), participants respond to different targets by pressing one of two different keys (e.g., the key on the left when $\mathrm{K}$ or $\mathrm{H}$ appear, and the key on the right when $\mathrm{C}$ or $\mathrm{S}$ are presented), while targets are surrounded by distracting flankers, which can be (1) identical to the target (e.g., KKKKK; identical trials), (2) perceptually different from the target but referring to the same response (e.g., HHKHH; compatible trials), (3) perceptually different from the target and referring to the opposite response (e.g., SSKSS; incompatible trials), and (4) perceptually different from the target without referring to any response (e.g., UUKUU; neutral trials). It has been repeatedly found that responses to identical and compatible trials are faster than those for neutral trials, and responses in incompatible trials are slower than in neutral trials. As pointed out by Prinz (2015), the comparisons involving the neutral trials are less conclusive because assignment (i.e., flankers may be assigned or not assigned to a response) and valence (i.e., flankers may be bivalent or univalent) are confounded in these comparisons. Consequently, it has been proposed that compatible (both target and flankers lead to the same responses) and incompatible (the target and flankers elicit correct and incorrect responses, respectively) trials should be compared, eliminating (or at least reducing) any confounding overlapping between assignment and valence (Prinz, 2015). As a result, interference is obtained, because response conflict is stronger in the incompatible trials than in the compatible trials, determining a Flanker (interference) effect. The interference effect in the Flanker task stems from a stimulus-stimulus overlap (i.e., target-flanker overlap; Kornblum \& Lee, 1995). The interference from a stimulusstimulus overlap is assumed to occur at a perceptual level (Kornblum et al., 1990), even if there is converging proof that the response interference, due to different responses being activated by target and flankers, arises at the level of response selection (Erikson \& Schultz, 1979). Using the joint paradigm, Atmaca et al. (2011; Peterburs et al., 2017) found a joint Flanker effect because each participant of the pair formed a representation of the co-actor's stimulus-response mapping, and incompatible flankers activated a representation of the co-actor's response due to a co-representation of one's own and the other's task rules. Atmaca et al. (2011) found a Flanker effect in both joint and individual conditions, but this effect was larger in the joint situation than in the individual one, suggesting evidence for action co-representation. 
According to the referential coding account, Dolk et al. (2014a) found a significant Flanker effect when participants performed a joint Flanker task either together with a human or next to a Japanese waving cat. As for the joint Simon effect, in the Flanker task a similar response discrimination problem exists, suggesting that participants are "more likely to increase the weight of features that discriminate their response from other events (joint condition), on top of the required stimulus discrimination (joint and solo condition)" (Dolk et al., 2014a, p. 1229). When a salient (human or nonhuman) event is introduced, a greater response discrimination is induced, and thus the impact of all flankers in the response competition increases (Peterburs et al., 2017). Recently, Dittrich et al. (2017) proposed a new explanation of the joint Flanker effect, after finding that joint Simon and Flanker effects were not driven by the same underlying processes. Manipulating the visibility of the co-actor (i.e., participants performed both tasks with or without a partition panel between them) in joint and individual conditions, the authors found a larger joint Flanker effect when participants were not separated by a partition panel, whereas the joint Simon effect was not affected by visibility manipulation. Dittrich et al. (2017) explained the joint Flanker effect as the result of less spatial attention in the joint task condition because of the presence and visibility of another person. This attentional-focus account can explain how the Flanker effect is modulated by the size of the focus of spatial attention (see Hübner, Steinhauser, \& Lehle, 2010, for a review) and can be considered an alternative interpretation of the results observed by Dolk et al. (2014a). In fact, the increase in the joint Flanker effect with a human or nonhuman co-actor might be due to the additional attention required to consider the co-actor, thereby consuming cognitive resources that are needed to focus spatial attention on the target position. In other words, a co-actor (or an inanimate object) attracts the participant's attention simply because the participant can see this co-actor. Thus, the participant is less able to focus on the (central) target in the joint condition compared to the individual condition, because more cognitive resources are required to monitor the co-actor (or the object). This involvement of cognitive resources is greater in a turn-taking response mode, which is the usual way to respond in the joint go/no-go task, as compared to continuous responding (Stenzel \& Liepelt, 2016), probably because an actor needs to distinguish his/ her turn (i.e., I-go) from the other's turn (i.e., You-go) when responding. The role of the cognitive resources in modulating the joint Flanker effect is compatible with results which demonstrate that high working memory load lead to an increase in the interference produced by a distractor in the classical Flanker task (Lavie, Hirst, de Fockert, \& Vidig, 2004). For instance, Fabbri and colleagues (Fabbri, Frisoni, Martoni, Tonetti, \& Natale, 2017, 2018) found a modulation of joint attention according to the different availability of cognitive resources during the day, confirming the shared attention theory. According to this theory, people devote greater cognitive resources to those features of their environment that are co-attended to simultaneously with others who are sitting next to them than to resources attended to at different times with strangers or alone (Shteynberg, 2015). The attentional-focus account, finally, could explain why PCC/TPJ patients exhibited a joint (Simon) effect when their attention was explicitly drawn to their co-actors while patients with frontal lobe lesions did not exhibit any joint effect, probably due to a different availability of the cognitive resources to represent or monitor the co-actors (Humphreys \& Bedford, 2011).

The purpose of the present study was to assess whether cognitive and affective ToM modulated the relationship between ToM and joint action in PD patients and HCs performing either a joint (go/no-go) or an individual Flanker task. In PD patients, affective (predominantly mediated by the frontostriatal-limbic circuitry) and cognitive (additionally mediated by the frontostriatal-dorsal circuitry) ToM functions have been differentiated (Bodden et al., 2010a; Kalbe et al., 2010). In addition, the ability to suppress automatic response activation in order to reduce interference (Ridderinkhof, van den Wildenberg, Segalowitz, \& Carter, 2004) seems to be implemented along frontal-basal ganglia circuits (Aron \& Poldrack, 2006), suggesting that PD patients are more vulnerable than healthy matched individuals to the interference produced by trials with incongruent flankers (Praamstra, Plat, Meyer, \& Horstinck, 1999; Praamstra, Stegeman, Cools, \& Horstink, 1998; Wylie, Stout, \& Bashore, 2005; Wylie, van den Wildenberg, Ridderinkhof, et al., 2009; but for mixed results see, Cagigas, Filoteo, Sticker, Rilling, \& Friedrich, 2007; Falkenstein, Willmssen, Hohnsbein, \& Hielscher, 2006; Lee, Wild, Holinagel, \& Grafman, 1999). Thus, joint and individual go/no-go versions of the Flanker task were suitable not only to assess the ability of PD patients and healthy controls (HCs) to inhibit competitive responses, but also to address the relationship between cognitive and affective ToM and joint action effect, considering that ToM may be built on more basic processes of social cognition, such as action control (and, particularly, the ability to inhibit responses in a go/no-go task; Sebanz, Knoblich, Stumpf, \& Prinz, 2005). Related to this last point, our study could add evidence to the failure of frontal patients to exhibit any ToM abilities or social Simon effect. The dorsolateral prefrontal cortex has usually been associated with the type of conflict (both stimulus conflict and response conflict) resolution (Egner, 2008) that is employed by participants in a task containing flankers, and our study could highlight the relationship between (cognitive) ToM and the joint Flanker effect. Finally, our study could test which account better explains the joint Flanker effect, considering that PD patients are not only impaired in both cognitive and affective ToM due to dysfunction of the frontostriatal circuitry but also show Flanker interference effects due to poorer inhibitory control and selective attention in 
processing the relevant target (resulting in a greater distraction in reaction to flankers; see Zgaljardic, Borod, Foldi, \& Mattis, 2003, for a review). For instance, according to the referential coding account, PD patients with a deficit in cognitive ToM may be impaired in action representation, and such an impairment could be linked to dysfunction in executive function, typically observed in PD, explaining the relationship between cognitive ToM and joint action in PD patients.

In the present study, we differentiated PD patients (clinical patients who were matched for socio-demographic variables) and HCs with high and low scores in specific cognitive and affective ToM tests, and we measured their joint Flanker effect (i.e., the difference between compatible and incompatible trials) when stimuli surrounded by flankers which were targets for their co-actor were presented. Similar to Atmaca et al. (2011), who recruited a different sample of participants to test the standard version of the Flanker task, we decided to test separate groups of PD patients and HCs in the two-choice version of the task to ensure that the material used in the social condition yielded a standard Flanker effect. Considering that we expected all participants to show a classical Flanker (interference) effect in the standard version of the task, any modulation of the Flanker interference effect in joint and individual tasks could be detected in relation to this "reference" value.

\section{Methods}

\section{Participants}

For the purpose of this research, the inclusion criteria were as follows: diagnosis of idiopathic PD according to the United Kingdom Parkinson's Disease Society brain bank (Gibb \& Lees, 1988); mild to moderate disease stage, as defined by Hoehn and Yahr (H\&Y) stages I and II; lack of PDassociated dementia (PDD) according to an algorithm for clinical diagnosis recommended by the MDS Task Force (Emre, Aarsland, Brown et al., 2007; Poewe, Gauthier, Aarsland, et al., 2008). In addition, we excluded patients who, in an Italian standardized version of the Mini-Mental State Examination (MMSE), obtained a total age-and-educationaladjusted score $<23.8$ (Folstein, Folstein, \& McHugh, 1975; Measso, Cavarzeran, Zappalà, et al., 1993). Furthermore, we excluded PD patients with major depression diagnosed by means of a structured interview based on the Diagnostic and Statistical Manual of Mental Disorders, $4^{\text {th }}$ Edition (DSM-IV) criteria (American Psychiatric Association, 1994). Patients with altered verbal comprehension with age-andeducational-adjusted score $\leq 26.25$ on the Token Test (Spinnler \& Tognoni, 1987) also were excluded. Ninety-five patients with Parkinson's disease met inclusion and exclusion criteria. All patients were in on state. Sixty PD patients were asked to perform the go/no-go Flanker task in the joint and individual conditions, while the remaining 35 patients performed the standard two-choice RT task. The choice to include 95 PD patients (and 95 healthy controls or HCs; see below) was grounded on the fact that other studies, in which ToM or flanker interference were investigated in the PD population, had a number of PD patients ranging from 7 (Praamstra et al., 1998) to 50 (Wylie et al., 2005). In addition, studies investigating joint action in normal individuals had a sufficient number of participants to create about 30 pairs (Atmaca et al., 2011; Sebanz et al., 2003). We believe that with the number of participants employed, we were able to attain adequate statistical power.

For each PD patient enrolled in the study, we selected control individuals with similar socio-demographic (age, education, and sex) features. Thus, 60 controls performed the go/nogo Flanker task in the joint and individual conditions, while the remaining $35 \mathrm{HCs}$ performed the standard Flanker task. The exclusion criteria were the same applied for PD patients, as described above. Table 1 resumes sociodemographic and clinical features of the participants in the study. The study was approved by the Department of Psychology of University of Campania and was performed in accordance with the ethical standards laid down in the 1964 Declaration of Helsinki. All participants gave their informed consent before their inclusion in the study.

\section{Materials}

\section{ToM abilities}

The Italian version of the Advanced Test of ToM (AT; Prior et al., 2003) was used to investigate the cognitive subcomponent of ToM, assessing the ability to attribute mental states to others. The task required participants to indicate the reason why the characters of 13 naturalistic stories, in which two or more characters interacted with each other as in familiar or social contexts (e.g., children arguing about who a toy belonged to) behaved as they did. A score of 1 was assigned for every correct response and, thus, the total score ranged from 0 (worst performance) to 13 (best performance). The guidelines suggest that only perfect performance (13/13) indicates a good cognitive ToM (and so just one error indicates a problem in cognitive ToM).

The modified Italian version of the Emotion Attribution Task (EAT; Prior et al., 2003) was administered to assess the affective subcomponent of ToM. In this case, participants were asked to indicate the type of emotion felt by main characters of 35 short stories, describing emotional situations (e.g., a man attacked by a big black spider). The emotions presented in the task were sadness, fear, embarrassment, disgust, happiness, anger, and envy. A score of 1 was assigned for every correct response, and thus, the total score ranged from 0 (worst 
Table 1 Sociodemographic and clinical features of PD patients and healthy controls (HC) for both social and classical two-choice conditions

Social condition

\begin{tabular}{|c|c|c|c|}
\hline & $\mathrm{PD}(\mathrm{n}=60)$ & $\mathrm{HC}(\mathrm{n}=60)$ & PD vs HC Comparisons \\
\hline Age (yr) & $63.98 \pm 9.30$ & $62.25 \pm 10.58$ & $t(118)=0.96, p=0.34$ Cohen's $d_{s}=0.17$ \\
\hline Gender (males/females) & $35 / 25$ & $27 / 33$ & $\chi^{2}(1)=2.14, p=0.14 w=0.13$ \\
\hline Education (yr) & $11.18 \pm 5.21$ & $11.57 \pm 5.25$ & $t(118)=-0.40, p=0.69$ Cohen's $d_{s}=-0.07$ \\
\hline PD duration & $5.94 \pm 4.52$ & - & - \\
\hline $\mathrm{H} \& \mathrm{Y}$ stage & $1.50 \pm 1.09$ & - & - \\
\hline UPDRS score & $12.64 \pm 7.23$ & - & - \\
\hline LEDD & $586.86 \pm 423.65$ & - & - \\
\hline MMSE & $27.80 \pm 1.73$ & $28.09 \pm 1.41$ & $t(118)=-1.02, p=0.31$ Cohen's $d_{s}=-0.18$ \\
\hline Token test & $31.19 \pm 1.84$ & $31.60 \pm 1.81$ & $t(118)=-1.24, p=0.22$ Cohen's $d_{s}=-0.22$ \\
\hline AT score (median value) & $7.18 \pm 2.39($ median $=8.00)$ & $9.77 \pm 1.53($ median $=10.00)$ & $t(118)=-7.05, p<0.0001$ Cohen's $d_{s}=-1.29$ \\
\hline EAT score (median value) & $21.38 \pm 5.98($ median $=21.00)$ & $26.23 \pm 3.32($ median $=26.50)$ & $t(118)=-5.49, p<0.0001$ Cohen's $d_{s}=-1.003$ \\
\hline RT joint task (in ms) & $1,443 \pm 642$ & $728 \pm 390$ & $t(118)=7.43, p<0.0001$ Cohen's $d_{s}=1.35$ \\
\hline Accuracy $(\%)$ joint task & $96.04 \pm 11.26$ & $95.56 \pm 8.64$ & $t(118)=0.27, p=0.79$ Cohen's $d_{s}=0.05$ \\
\hline RT individual task (in ms) & $1559 \pm 741$ & $834 \pm 521$ & $t(118)=6.20, p<0.0001$ Cohen's $d_{s}=1.13$ \\
\hline Accuracy $(\%)$ individual task & $97.57 \pm 7.83$ & $97.22 \pm 9.75$ & $t(118)=0.22, p=0.83$ Cohen's $d_{s}=0.04$ \\
\hline \multicolumn{4}{|l|}{ Standard two-choice condition } \\
\hline & $\mathrm{PD}(\mathrm{n}=35)$ & $\mathrm{HC}(\mathrm{n}=35)$ & PD vs HC Comparisons \\
\hline Age (years) & $67.17 \pm 10.46$ & $65.86 \pm 8.54$ & $t(68)=0.58, p=0.57$ Cohen's $d_{s}=0.13$ \\
\hline Gender (males/females) & $19 / 16$ & $17 / 18$ & $\chi^{2}(1)=0.23, p=0.63 w=0.06$ \\
\hline Education (years) & $11.08 \pm 5.11$ & $11.91 \pm 4.95$ & $t(68)=-0.69, p=.049$ Cohen's $d_{s}=-0.16$ \\
\hline PD duration & $5.04 \pm 4.61$ & - & - \\
\hline $\mathrm{H} \& \mathrm{Y}$ stage & $2.00 \pm 1.53$ & - & - \\
\hline UPDRS score & $12.28 \pm 5.85$ & - & - \\
\hline LEDD & $544.14 \pm 617.81$ & - & - \\
\hline MMSE & $27.48 \pm 1.98$ & $27.41 \pm 1.56$ & $t(68)=0.15, p=0.88$ Cohen's $d_{s}=0.04$ \\
\hline Token test & $30.80 \pm 2.32$ & $31.33 \pm 1.99$ & $t(68)=-1.02, p=0.31$ Cohen's $d_{s}=-0.25$ \\
\hline RT (in ms) & $2068 \pm 1344$ & $846 \pm 234$ & $t(68)=5.30, p<0.0001$ Cohen's $d_{s}=1.27$ \\
\hline Accuracy $(\%)$ & $96.79 \pm 7.62$ & $95.42 \pm 10.18$ & $t(68)=0.64, p=0.53$ Cohen's $d_{s}=0.15$ \\
\hline
\end{tabular}

Significant differences are in bold

PD, Parkinson's disease; HC, healthy controls; H\&Y, Hoehn and Yahr stage; UPDRS, Unified Parkinson's Disease Rating Scale; LEDD, L-dopa equivalent daily dose; MMSE, Mini-Mental State Examination; AT, Advanced test of ToM; EAT, Emotion Attribution Task of ToM; RT, reaction time

performance) to 35 (best performance). As in the AT test, only perfect performance $(35 / 35)$ indicates a good affective ToM (and so just one error indicates a problem in affective ToM).

\section{Flanker task}

All participants performed a letter version of the Flanker task (Eriksen \& Eriksen, 1974). Participants were presented an array of five letters, and they were instructed to respond to the letter in the middle position, that is, the target letter. The target letters were $\mathrm{H}, \mathrm{K}, \mathrm{S}$, and $\mathrm{C}$, with $\mathrm{H}$ and $\mathrm{K}$ assigned to one response key and $\mathrm{S}$ and $\mathrm{C}$ to the other key. The target letter could be flanked by $\mathrm{H}, \mathrm{K}, \mathrm{C}, \mathrm{S}$, and $\mathrm{U}$ (which was never a target). The combination of targets and flankers determined four types of array: identical, compatible, neutral, and incompatible trials. For instance, if the target letter was $\mathrm{H}$, then the identical trial was $\mathrm{HHHHH}$, the compatible trial was KKHKK, the neutral array was UUHUU, and the incompatible type was SSHSS or CCHCC. The response keys were the " $z$ " key and the " 3 " key on the numerical keypad of a standard keyboard. If participants performed a two-choice task (standard Flanker task), then the $\mathrm{z}$ button was pressed with the left index finger, whereas the 3 button was pressed with the right index finger. When the joint and individual conditions were administered (for details and illustrations of joint and individual conditions see Atmaca et al., 2011, Fig. 1, p. 372), participants pressed the corresponding response key with the index finger of their dominant hand. Regarding the handedness of participants, 18 participants were lefthanders, and the number of lefthanders between groups did not differ. In order to prevent both actors from involuntarily interfering with each other's responses, individuals were positioned 

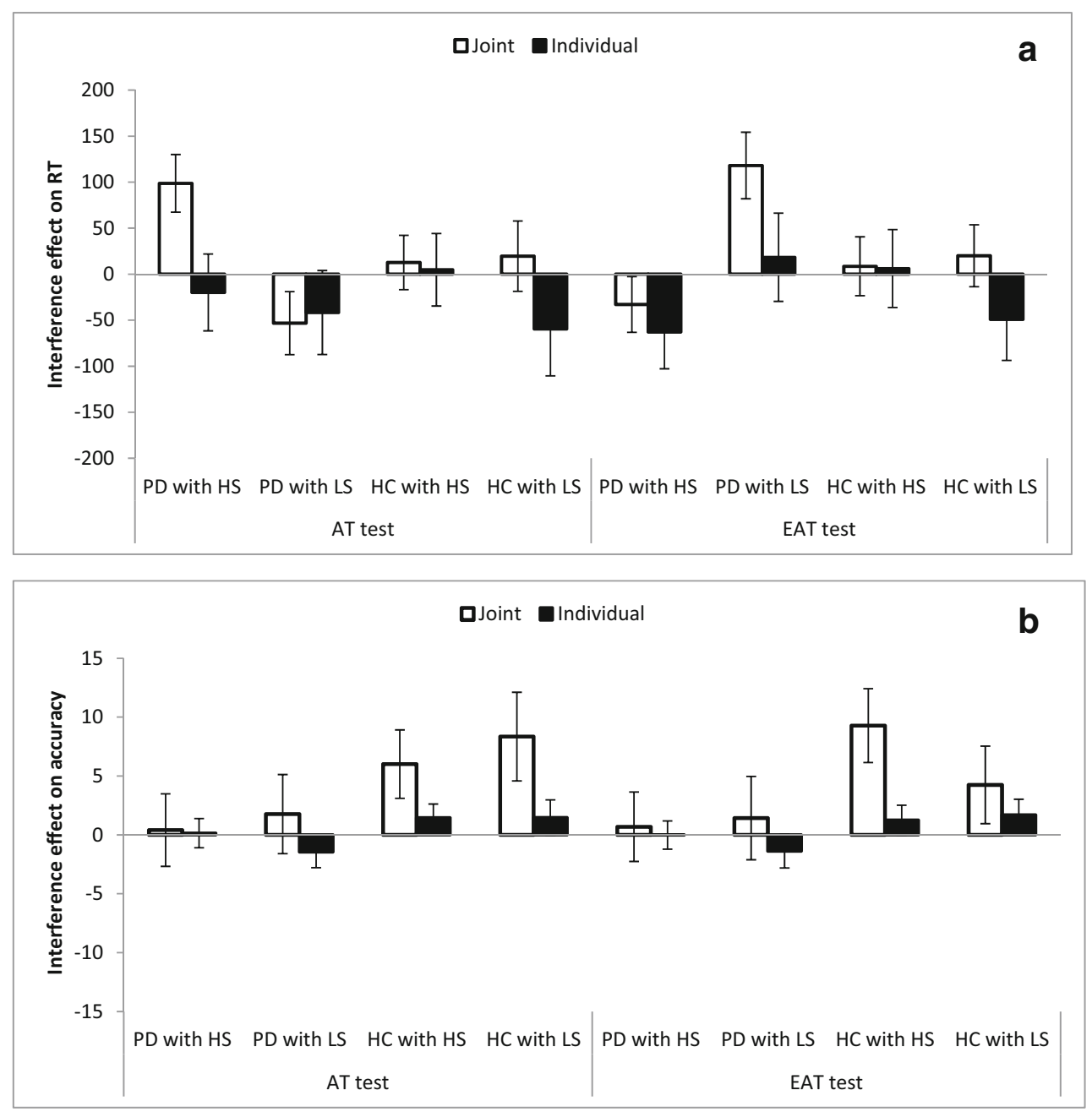

Fig. 1 a) RT interference effect (in ms), calculated as the difference between RTs in incompatible trials and RTs in congruent trials (defined as the mean performance in compatible trials) for both PD patients and healthy controls (HC), according to categorization (HS = high scores; LS = low scores) in AT and EAT tests, in both joint (white histogram) and individual (black histogram) conditions. b) Accuracy interference effect (in \%), calculated as the difference between percentage of correct

depending on their handedness in the only situation in which left-handed and right-handed participants performed the joint task altogether. The main difference between individual and joint conditions was that in the latter condition two participants were sitting side by side, whereas in the former condition there was an empty chair beside the single participant. The joint task was always performed by two PD patients or by two HCs at the same time, and we decided not to create mixed (PD and $\mathrm{HC}$ ) pairs or use a confederate as co-actor. In all samples, there were 32 male-male pairs, 29 female-female pairs, and 59 mixed pairs. Target letter pairs (H-K vs. S-C) and response keys (left $\mathrm{z}$ vs. right 3 key) were counterbalanced across participants. Importantly, each participant sat in the same chair and responded to the same target pair with the same key throughout the entire experiment. In the twochoice condition, the combinations of target pairs (H-K vs. responses in compatible trials and percentage of correct responses in incompatible trials, for both PD patients and healthy controls (HC), according to categorization (HS = high scores; LS = low scores) in AT and EAT tests in both joint (white histogram) and individual (black histogram) conditions. In both panels, a positive difference indicates a Flanker interference effect (while a negative difference indicates a reversed Flanker effect) and bars represent standard errors

S-C) and response key (left vs. right) also were counterbalanced across participants. In both the joint and individual conditions, we measured RTs and accuracy for all flanker arrays, as well as the accuracy in abstaining from providing a response for all no-go trials. This last measure was considered as an index that participants correctly understood the joint procedure. In the standard Flanker task, RTs and accuracy for all flanker arrays were recorded.

The stimuli presentation and response collection in the Flanker task were controlled via computer using the software package E-Prime version 2.0 (Psychology Software Tools, Inc.). Following the criteria of Atmaca et al. (2011), each trial started with a white fixation cross (font: Times New Roman, 40 points size in bold) at the center of a black screen for 500 ms. Then, a black screen appeared for $500 \mathrm{~ms}$, followed by a letter array (in the same font as that of the fixation cross), 
which remained on the screen for $15,000 \mathrm{~ms}$ or until a response was given, taking into account that PD patients have deficits in motor functions. When a response key was pressed or the time elapsed, there was an intertrial interval of 1,000 $\mathrm{ms}$. In both the joint and individual conditions, there were 48 trials ( 24 go, and 24 no-go trials) in which all four trial types occurred equally often. In each experimental block, the trials were presented in random order. The same number of trials and type of presentation was adopted in the two-choice Flanker task. Independently from the experimental situations, all participants were trained with 16 trials, and feedback regarding response speed and accuracy was provided. If further training was required by participants in the two-choice task, as well as by one or both co-actors in the other two conditions, the training session was performed again before the experimental session. In both joint and individual Flanker tasks as well as in the standard version of the Eriksen flanker task, all participants were instructed to respond as fast and as accurately as possible.

\section{Procedure}

All patients and HCs underwent the same procedure in the joint condition. When a pair of participants arrived at the laboratory, one member of the pair was administered both the AT and EAT individually, while the other one was administered the individual go/no-go Flanker task. Afterwards, the pair performed the joint Flanker task, and at the end of the task the AT and EAT tests were administered to the member of the pair who started with the computer version of the task, while the other participant remained seated to perform his/her version of the individual go/no-go Flanker task. At the end of the procedure, both participants were debriefed. The administration of the AT and EAT tests, as well as the individual Flanker task, was done in two separate rooms. The order of the AT and EAT tests, as well as the participant's position (sitting on the left or right seat), was counterbalanced between participants.

All PD patients and HCs in the two-choice condition performed the Flanker task, and at the end they were debriefed. The assignment of response keys and letter target pairs was counterbalanced between participants.

\section{Data Analysis}

As reported earlier, in both the AT and EAT tests the presence of only one error indicated a problem in cognitive and/or affective ToM abilities. Accordingly, we found that $2.5 \%$ of the whole sample failed to show a cognitive problem while all participants resulted to have an affective problem. We obtained similar mean scores and variability for the AT and EAT tests as those previously reported by Santangelo et al. (2012; see Table 2 on page 102) with a sample of PD patients and controls who had similar socio-demographic and clinical features as those reported in our study. Taking this into account, we decided to split the participants for each ToM test into two subgroups: participants with low scores compared to the median of score distribution of the corresponding group versus participants with high scores compared to the median of score distribution of the corresponding group (Table 2). Even though we used this arbitrary categorization in which we could not associate low scores with a deficit in this specific ToM subcomponent (and high scores with a lack of deficit), we could assess the influence of the two subcomponents of ToM on the joint action, creating four categories: PD patients and HCs with low scores in cognitive and affective ToM tests, and PD patients and HCs with high scores in cognitive and affective ToM tests (Tables $2 \mathrm{a}$ and $\mathrm{b}$ ). This assumption was grounded on the positive correlation between AT scores and tests assessing frontal lobe functioning (higher AT score associated with higher frontal lobe functions) and the negative correlation between EAT scores and tests assessing behavioural disorders and apathy (higher EAT scores and lower behavioural disorders and apathy) found by Santangelo et al. (2012). The distribution of participants with higher or lower scores in both ToM tests were similar between PD patients and HCs (AT categorization: $\chi^{2}(1)=0.85, p=0.36, w=0.08$; EAT categorization: $\chi^{2}(1)=0.54, p=0.46, w=0.07$ ).

To compare joint and individual Flanker effects, as well as performance in the two-choice Flanker task, in terms of RTs, we decided to calculate a Flanker interference effect by subtracting congruent trials (defined as the mean value of compatible trials; Atmaca et al., 2011; Prinz, 2015) from incongruent trials. Thus, a positive difference indicated an interference effect, whereas a negative difference indicated a reversed Flanker effect. We decided to apply this index, because PD patients are slower in their responses and more error prone than controls (Praamstra et al., 1998, 1999; Wylie et al., 2005, 2009), making the group comparisons more difficult. In both the joint and individual conditions, the Flanker interference effect was calculated for RTs of correct trials, excluding (i.e., considering them as outliers) all RTs lower or greater than 3 SD and all correct trials following an error due to post error slowing (Dutilh, Vandekerckhove, Forstmann, et al., 2012). The Flanker interference effect was calculated for accuracy (defined as percentage of correct response), with the only difference that the accuracy of incongruent trials was subtracted from that of congruent trials. Thus, a positive difference indicated an interference effect while a negative difference indicated a reversed Flanker effect. Specifically, we transformed the accuracy data into a more normalized shape using arcsin transformation, and then we calculated the Flanker interference effect for accuracy on arcsin-transformed percentages of correct responses. For the descriptive data (means and SD), we reported original percentages for clarity, as well as the interference effect expressed in percentage difference. In the standard Flanker task, the same Flanker interference 
Table 2 A) Comparisons between PD patients (PD) with low scores (LS: below the median; $\mathrm{n}=29$ ) and high scores (HS: above the median; $\mathrm{n}$ = 31) in AT test for sociodemographic and clinical features; the same comparisons are also displayed for healthy controls (HC) with LS ( $\mathrm{n}=$ $21)$ and HS $(n=36)$ in AT test for sociodemographic variables. B) The comparisons between PD patients (PD) with low scores (LS: below the median; $\mathrm{n}=26$ ) and high scores (HS: above the median; $\mathrm{n}=34$ ) in EAT test for sociodemographic and clinical features; the same comparisons are also displayed for healthy controls $(\mathrm{HC})$ with LS $(\mathrm{n}=30)$ and HS $(\mathrm{n}=30)$ in EAT test for sociodemographic variables

\begin{tabular}{|c|c|c|c|c|}
\hline A & & LS in AT test & HS in AT test & Comparisons \\
\hline \multirow[t]{2}{*}{ Age $(y r)$} & PD & $64.03 \pm 9.92$ & $63.94 \pm 8.85$ & $t(58)=0.04, p=0.97$ Cohen's $d_{s}=0.01$ \\
\hline & HC & $66.83 \pm 10.06$ & $59.19 \pm 9.90$ & $t(58)=2.91, p<0.05$ Cohen's $d_{s}=0.76$ \\
\hline \multirow[t]{2}{*}{ Gender (males/females) } & PD & $20 / 9$ & $15 / 16$ & $\chi^{2}(1)=2.61, p=0.11 w=0.21$ \\
\hline & $\mathrm{HC}$ & $9 / 15$ & $18 / 18$ & $\chi^{2}(1)=0.91, p=0.34 w=0.12$ \\
\hline \multirow[t]{2}{*}{ Education (yr) } & PD & $9.83 \pm 4.80$ & $12.45 \pm 5.34$ & $t(58)=1.99, p=0.05$ Cohen's $d_{s}=0.52$ \\
\hline & $\mathrm{HC}$ & $10.00 \pm 4.71$ & $12.61 \pm 5.39$ & $t(58)=-1.93, p=0.058$ Cohen's $d_{s}=0.51$ \\
\hline \multirow[t]{2}{*}{ PD duration } & PD & $6.18 \pm 4.84$ & $5.73 \pm 4.32$ & $t(58)=0.34, p=0.74$ Cohen's $d_{s}=0.09$ \\
\hline & $\mathrm{HC}$ & - & - & - \\
\hline \multirow[t]{2}{*}{ H\&Y stage } & PD & $1.71 \pm 1.50$ & $1.31 \pm 0.59$ & $U=30.50, Z=0.05, p=.96, r=0.01$ \\
\hline & $\mathrm{HC}$ & - & - & - \\
\hline \multirow[t]{2}{*}{ UPDRS score } & PD & $14.24 \pm 6.83$ & $11.21 \pm 7.40$ & $t(58)=1.54, p=0.13$ Cohen's $d_{s}=0.40$ \\
\hline & $\mathrm{HC}$ & - & - & - \\
\hline \multirow[t]{2}{*}{ LEED } & PD & $1249.30 \pm 3442.99$ & $527.93 \pm 397.77$ & $t(58)=1.08, p=0.29$ Cohen's $d_{s}=0.28$ \\
\hline & $\mathrm{HC}$ & - & - & - \\
\hline \multirow[t]{2}{*}{ AT score } & PD & $5.28 \pm 1.85$ & $8.97 \pm 1.11$ & $t(58)=-9.45, p<0.0001$ Cohen's $d_{s}=2.48$ \\
\hline & $\mathrm{HC}$ & $8.25 \pm 0.94$ & $10.78 \pm 0.87$ & $t(58)=-10.69, p<0.0001$ Cohen's $d_{s}=2.81$ \\
\hline $\mathrm{B}$ & & LS at EAT test & HS at EAT test & Comparisons \\
\hline \multirow[t]{2}{*}{ Age (yr) } & PD & $67.38 \pm 7.85$ & $61.38 \pm 9.59$ & $t(58)=2.59, p<0.05$ Cohen's $d_{s}=0.68$ \\
\hline & $\mathrm{HC}$ & $63.43 \pm 10.41$ & $61.07 \pm 10.79$ & $t(58)=0.87, p=0.39$ Cohen's $d_{s}=0.22$ \\
\hline \multirow[t]{2}{*}{ Gender (males/females) } & PD & $14 / 12$ & $21 / 13$ & $\chi^{2}(1)=0.38, p=0.54 w=0.07$ \\
\hline & $\mathrm{HC}$ & $10 / 20$ & $17 / 13$ & $\chi^{2}(1)=3.30, p=0.07 w=0.23$ \\
\hline \multirow[t]{2}{*}{ Education (yr) } & PD & $10.73 \pm 5.85$ & $11.53 \pm 4.73$ & $t(58)=-0.59, p=0.56$ Cohen's $d_{s}=0.15$ \\
\hline & $\mathbf{H C}$ & $10.17 \pm 5.66$ & $12.97 \pm 4.48$ & $t(58)=-2.13, p<0.05$ Cohen's $d_{s}=0.56$ \\
\hline \multirow[t]{2}{*}{ PD duration } & PD & $6.36 \pm 5.05$ & $5.58 \pm 4.09$ & $t(58)=0.60, p=0.55$ Cohen's $d_{s}=0.16$ \\
\hline & HC & - & - & - \\
\hline \multirow[t]{2}{*}{ H\&Y stage } & PD & $1.80 \pm 1.79$ & $1.35 \pm 0.58$ & $U=24.50, Z=0.28, p=.78, r=0.07$ \\
\hline & HC & - & - & - \\
\hline \multirow[t]{2}{*}{ UPDRS score } & PD & $13.88 \pm 7.88$ & $11.54 \pm 6.55$ & $t(58)=1.18, p=0.24$ Cohen's $d_{s}=0.31$ \\
\hline & HC & - & - & - \\
\hline \multirow[t]{2}{*}{ LEED } & PD & $1253.28 \pm 3589.93$ & $574.38 \pm 418.02$ & $t(58)=1.01, p=0.32$ Cohen's $d_{s}=0.26$ \\
\hline & $\mathrm{HC}$ & - & - & - \\
\hline \multirow[t]{2}{*}{ AT score } & PD & $15.85 \pm 3.63$ & $25.62 \pm 3.37$ & $t(58)=-10.77, p<0.0001$ Cohen's $d_{s}=2.82$ \\
\hline & $\mathrm{HC}$ & $23.40 \pm 1.92$ & $29.07 \pm 1.44$ & $t(58)=-12.93, p<0.0001$ Cohen's $d_{s}=3.40$ \\
\hline
\end{tabular}

In both tables, significant differences are in bold

PD, Parkinson's disease; HC, healthy controls; H\&Y, Hoehn and Yahr stage; UPDRS, Unified Parkinson's Disease Rating Scale; LEDD, L-dopa equivalent daily dose; AT, Advanced test of ToM; EAT, Emotion Attribution Task of ToM

effects also were calculated for RTs of correct trials (with the previous definition of outliers) and accuracy after arcsin transformation.

As shown in Table 2a, PD patients with high scores in the AT test had more years of education than PD patients with low scores in the AT test. In addition, HCs with high scores in the AT test were younger than HCs with low AT scores. In Table $2 \mathrm{~b}$, HCs with high EAT scores had more years of education than HCs with low scores in the EAT test. Furthermore, PD patients with high scores in the EAT test were younger than PD patients with low scores. Thus, in the social condition (joint vs. individual), we performed mixed ANCOVAs with Group (PD patients vs. HCs) and AT Category (low score vs. high score), as between-subjects factors, and Task Condition (joint vs. individual), as a withinsubjects factor on RT and accuracy Flanker interference 
effects, using age and education as covariates. The same ANCOVAs were carried out using EAT Category (low score vs. high score) in substitution of AT categorization. Considering the arbitrary nature of our categorization, we further performed two multiple regressions predicting the interference effect in joint or individual conditions using a model in which age, education, and cognitive and affective ToM scores were all entered. Finally, we ran correlations between Flanker interference effects and clinical features of PD patients to ensure that this effect was associated with the clinical nature of PD.

In the two-choice (classical) condition, betweensubjects t-tests were run on RT and accuracy Flanker interference effects, comparing PD patients with healthy controls. The same correlation analyses were also carried out in these PD patients. For all analyses, effect sizes were reported following the recommendation of Lakens (2013). The alpha level was set at 0.05 .

\section{Results}

\section{Social condition}

According to outlier criteria, we excluded 3 PD patients and 3 $\mathrm{HC}$ individuals from the analyses, due to lower accuracy (below $50 \%$ ) either in the joint or individual condition or in both. ${ }^{1}$ The mean accuracy in inhibiting responses in no-go trials for PD patients was equal to $96.64 \%$ ( $\mathrm{SD}=13.98 \%$ ), while for HCs it was equal to $98.80 \%(\mathrm{SD}=3.63)$, and the comparison was not significantly different $(t(112)=-1.11, p=0.27$, Cohen's $\left.d_{s}=0.21\right)$. Overall, all participants understood the joint procedure and performed the tasks accurately. All descriptive data for RTs and accuracy for each trial in both social

\footnotetext{
${ }^{1}$ After applying outliers criteria, we counted 31 male-male pairs, 57 mixedgender pairs, and 26 female-female pairs. However, the distribution of these three types of gender pairs was significantly different between PD patients and HCs $\left(\chi^{2}(2)=7.25, p<0.05, w=0.25\right)$, because only 7 female-female pairs were included within PD group. This result was expected because PD affects more men than women (with a ratio of approximately $2: 1$; e.g., Miller \& Cronin-Golomb, 2010). Nevertheless, two recent studies found that the gender composition of the two actors involved in the share task modulated the joint (Simon) effect (Mussi, Marino, \& Riggio, 2015; van der Weiden, Aarts, Prikken, \& van Haren, 2016). Thus, we decided to run two mixed ANCOVAs with Gender Pair (male-male, female-female and mixed pair) as between-subjects factor and Task Condition (joint vs. solo) as within-subjects factor on both RTs and arcsin transformed accuracy, using age, education, AT and EAT scores as covariates. The ANCOVA on RTs revealed a significant Task Condition effect $\left(F(1,107)=9.44, p<0.005, \eta_{p}^{2}=0.081\right)$, while a main Gender Pair effect $\left(F(1,107)=2.09, p=0.13, \eta_{p}^{2}=0.038\right)$ and a Gender Pair $\mathrm{x}$ Task Condition interaction $\left(F(1,107)=0.63, p=0.53, \eta_{p}^{2}=0.012\right)$ were not significant. The same ANCOVA on Flanker effect for the accuracy did not reveal any significant main effects (Gender Pair: $F(1,107)=2.40, p=0.09, \eta_{p}^{2}$ $=0.043$; Task Condition: $\left.F(1,107)=0.57, p=0.45, \eta_{p}^{2}=0.005\right)$ or interaction $\left(F(1,107)=0.66, p=0.52, \eta_{p}^{2}=0.012\right)$. Consequently, in our study, the gender composition of pairs did not modulate the general findings.
}

(joint and individual) conditions, as well as for the two-choice task are displayed in Supplementary Material (Table S3), for both PD patients and HCs with higher and lower scores at and EAT, separately.

The Group x AT Category x Task Condition ANCOVA on RT interference effect revealed a significant Task Condition effect $\left(F(1,108)=5.68, p<0.05, \eta_{p}^{2}=0.05, \eta_{G}^{2}=0.02\right)$, suggesting a Flanker effect for the joint condition $(+19.44 \mathrm{~ms} \pm 168.64 \mathrm{~ms})$, whereas a reversed Flanker effect was perceptible in the individual condition $(-29.07 \mathrm{~ms} \pm$ $229.94 \mathrm{~ms}$ ). The other two main effects did not reach statistical significance (Group: $F(1,108)=0.003, p=0.96, \eta_{p}^{2}=$ 0.0001, $\eta_{G}^{2}=0.0001$; AT Category: $F(1,108)=3.26, p=$ $\left.0.07, \eta_{p}^{2}=0.03, \eta_{G}^{2}=0.03\right)$. The ANCOVA did not reveal any two-way interactions (all $F_{\mathrm{S}}<1.00$ with $p \mathrm{~s}>0.30$ and $\eta_{p s}^{2}$ $<0.008$ or $\left.\eta_{G}^{2}<0.01\right)$. Finally, the triple interaction was significant $\left(F(1,108)=4.42, p<0.05, \eta_{p}^{2}=0.04, \eta_{G}^{2}=\right.$ 0.01 ), as shown in Fig. 1a. The interference effect was higher in the joint than in the individual condition for PD patients with high scores in the AT test $(t(30)=2.90, p=0.007)$, whereas there was no difference in interference effect between joint and individual tasks for PD patients with low scores in the AT test $(t(25)=-0.16, p=0.87)$. In $\mathrm{HCs}$ the interference effect did not differ between the joint and individual condition either for individuals with high scores $(t(35)=0.56, p=0.58)$ or those with low scores $(t(20)=1.45, p=0.16$ at test $)$.

The same ANCOVA on accuracy interference effect showed no main effects or significant interactions (all $F$ s $<$ 1.30 , with $p s>0.20$ and $\eta_{p s}^{2}<0.01$ or $\left.\eta_{G}^{2}<0.01\right)$, as displayed in Fig. 1b, with the exclusion of a main Group effect $\left(F(1,108)=5.51, p<0.05, \eta_{p}^{2}=0.05, \eta_{G}^{2}=0.02\right)$, suggesting that the Flanker effect was higher for $\mathrm{HCs}(+4.32 \% \pm 13.21 \%)$ than for patients $(0.22 \% \pm 9.69 \%)$.

The Group x EAT Category x Task Condition ANCOVA on RT interference effect confirmed a main Task Condition effect $\left(F(1,108)=6.12, p<0.05, \eta_{p}^{2}=0.04, \eta_{G}^{2}=0.02\right)$, suggesting a Flanker effect in the joint task $(+28.49 \mathrm{~ms} \pm$ $164.47 \mathrm{~ms}$ ) and a reversed effect in the individual task $(-21.89 \pm 219.96 \mathrm{~ms})$. The other two main effects did not reach statistical significance (Group: $F(1,108)=0.21, p=$ $0.65, \eta_{p}^{2}=.002, \eta_{G}^{2}=0.001$; EAT Category: $F(1,108)=$ $\left.2.32, p=0.13, \eta_{p}^{2}=0.02, \eta_{G}^{2}=0.01\right)$. None of the interactions were significant (all $F_{\mathrm{S}}<2.00$ with $p \mathrm{~s}>0.15$ and $\eta_{p s}^{2}<$ 0.02 or $\eta_{G}^{2}<0.01$ ), with the exception of the interaction between Group and EAT Category $(F(1,108)=5.04, p<$ $\left.0.05, \eta_{p}^{2}=0.05, \eta_{G}^{2}=0.03\right)$, as displayed in Fig. 1a. PD patients with low scores $(+68.20 \mathrm{~ms} \pm 253.27 \mathrm{~ms})$ had a greater interference effect than PD patients with high scores $(-47.83 \mathrm{~ms} \pm 206.87 \mathrm{~ms})$ in the EAT test, with $p<0.05$. By contrast, HCs with high scores $(+7.32 \mathrm{~ms} \pm 68.17 \mathrm{~ms})$ showed a larger Flanker effect than HCs with low scores $(-14.60 \mathrm{~ms} \pm$ $240.56 \mathrm{~ms})(p<0.05)$. 
Table 3 Regression models (standardized betas and significance levels) for social and individual conditions separately

\begin{tabular}{|c|c|c|c|c|c|c|c|c|}
\hline & \multicolumn{4}{|c|}{ Joint condition } & \multicolumn{4}{|c|}{ Individual condition } \\
\hline & $\beta$ & $\mathrm{t}$ & $p$ & $95 \% \mathrm{CI}$ & $\beta$ & $\mathrm{t}$ & $p$ & $95 \% \mathrm{CI}$ \\
\hline Age & +0.10 & 1.05 & 0.30 & $-1.56 / 5.08$ & -0.20 & -2.05 & $<0.05$ & $-9.24 /-0.16$ \\
\hline Education & +0.17 & 1.82 & 0.07 & $-0.51 / 12.07$ & -0.01 & -0.12 & 0.91 & $-9.08 / 8.09$ \\
\hline AT scores & +0.21 & 2.01 & $<0.05$ & $0.22 / 31.79$ & +0.003 & 0.03 & 0.98 & $-21.29 / 21.85$ \\
\hline EAT scores & -0.41 & -3.92 & $<0.0001$ & $-21.17 /-6.96$ & +0.03 & 0.24 & 0.81 & $-8.51 / 10.90$ \\
\hline Adjusted $R^{2}$ & .12 & & & & .01 & & & \\
\hline
\end{tabular}

Significant predictors are in bold

The same ANCOVA on accuracy interference effect confirmed the Group effect $\left(F(1,108)=5.18, p<0.05, \eta_{p}^{2}=0.05\right.$, $\left.\eta_{G}^{2}=0.02\right)$ with a greater Flanker effect for HCs $(+4.12 \% \pm$ $12.92 \%)$ than for PD patients $(+0.18 \% \pm 10.46 \%)$. No other main effects or interactions were statistically reliable (all $F_{\mathrm{s}}<$ 1.70 , with $p$ s $>0.25$ and $\eta_{p s}^{2}<0.01$ or $\left.\eta_{G}^{2}<0.005\right)$, as displayed in Fig. $1 b$.

In the joint conditions, the regression model was significant $(F(4,109)=4.80, p<0.001)$, explaining $12 \%$ of the variance. As reported in Table 4, the standardized $\beta$ values of AT and EAT scores were significant, confirming the results of the ANCOVAs (i.e., higher scores of cognitive ToM predicted a higher RT interference effect while lower scores of affective ToM predicted a higher RT interference effect). By contrast, the regression model in the individual condition was not significant $(F(4,109)=1.20$, $p=0.32$ ), as also shown by a lack of significant standardized $\beta$ values of AT and EAT scores, while age was a significant negative predictor (Table 3).

Finally, in PD patients, no significant correlations were found between RT interference effects and demographic characteristics or clinical features (all $r$ s ranging from -0.40 to +0.17 with $p$ s $>0.10$ ).

\section{Two-choice task}

According to outlier criteria, we removed five PD patients and two $\mathrm{HC}$ from the analysis due to their low level of accuracy $(<50 \%)$. When PD patients $(+101.79 \mathrm{~ms} \pm 250.41 \mathrm{~ms})$ and HCs $(+24.45 \mathrm{~ms} \pm 98.19 \mathrm{~ms})$ performed the classical Flanker task, both groups showed an RT interference effect, which was not different between groups $(t(61)=1.64, p=0.11$, Cohen's $\left.d_{s}=0.41\right)$. PD patients $(+0.83 \% \pm 9.38 \%)$ and $\mathrm{HCs}(+0.76 \% \pm$ $8.93 \%)$ exhibited similar accuracy in the Flanker effect $(t(61)$ $=0.03, p=0.97$, Cohen's $d_{s}=0.01$ ).

As before, in PD patients, no significant correlations were found between RT and accuracy interference effects and demographic characteristics or clinical features (all $r$ s ranging from -0.69 to +0.27 with $p$ s $>0.08$ ) .

\section{Discussion}

The purpose of the present study was to assess how ToM, with its subcomponents, influenced the joint effect in a Flanker task performed by PD patients and matched HCs, when two response alternatives were distributed among pairs of participants during a go/no-go Flanker task performed in joint (with a co-actor) and individual conditions. In addition, a different sample of PD patients and matched HCs performed the standard two-choice Flanker task to ensure that the material used in the social condition yielded a comparable standard Flanker effect.

In a large sample of PD patients and HCs, we found that cognitive ToM was associated with a joint Flanker effect. When all participants were arbitrarily categorized into individuals with high or low scores in the AT test, we found that PD patients with high scores exhibited a joint Flanker effect (Atmaca et al., 2011; Peterburs et al., 2017), whereas patients with low scores did not. As shown in Fig. 1a, all HCs exhibited a joint Flanker effect, even if this effect was not significantly different between joint and individual conditions for HCs with both high and low scores. Finally, in the regression analysis, the AT score was a significant predictor of the interference effect found in the joint but not in the individual condition, suggesting that higher AT scores were associated with a higher joint Flanker effect. These findings revealed that cognitive ToM may modulate a joint action effect. Even if the present study was behavioural, a possible explanation for the involvement of cognitive ToM in predicting the joint action effect could rely on the fact that the right-hemispheric dorsolateral prefrontal cortex is mainly involved in cognitive ToM (Kalbe et al., 2010; Kobayashi, Glover, \& Temple, 2007; Sommer, Dohnel, Sodian, et al., 2007). It has been proposed that this neural area is involved in reducing the conflict in the Flanker task that is due to an incongruence between the flankers and the target to be detected, and thus it has been associated with conflict resolution (Botvinick, Braver, Carter, \& Cohen, 2001; Durston, Davidson, Thomas, et al., 2003; Egner, 2008; Zmigrod, Zmigrod, \& Hommel, 2016). Even if we recognize that our procedure did not allow us to 
test cognitive ToM-impaired and unimpaired PD patients, our data showed that PD patients with higher scores in the AT test showed a joint Flanker effect, whereas PD patients with lower scores did not. This finding could be considered to be in line with the outcomes reported by Costa et al. (2013), who found that only PD patients with an alteration of executive function had deficits in ToM task performance, whereas PD patients with unimpaired executive functioning performed faux pas stories accurately. In addition, our results may be considered to be in line with the associations between cognitive ToM and frontal abilities (e.g., sensitivity to interference or inhibitory control) found by Santangelo et al. (2012), suggesting that deficits in cognitive ToM reflect a widespread frontal dysfunction due to an impairment of mainly dorsolateral prefrontal areas. Thus, we can speculate that a "preserved" cognitive ToM is necessary for action representation, also considering that frontal lobe patients failed in ToM tasks and did not exhibit any joint action effect (Humphreys \& Bedford, 2011). In a similar way, it has been observed that frontal areas are active in go-trials in a joint Simon task compared with the individual situation, suggesting that these areas reflect increased selfreflective processing during go-trials (Wen \& Hsieh, 2015). The Flanker effect shown by PD patients (Praamstra et al., 1998, 1999; Wylie et al., 2005, 2009) and HCs (Eriksen \& Eriksen, 1974) in the two-choice Flanker task may support the relevance of executive control. The standard Flanker effect is assumed to arise at the level of response selection, because target and flankers activate two different responses (Eriksen \& Schultz, 1979), and this interference effect is usually greater among PD patients due to an alteration of frontal-basal ganglia circuits. According to the action co-representation account, the joint Flanker effect could be explained in a similar way. Thus, slower RTs on incompatible trials could reflect a response selection conflict, because each participant forms a representation of the co-actor's task instructions (Sebanz et al., 2003, 2005), and incompatible flankers activate the representation of the co-actor's response (Atmaca et al., 2011). Indeed, in ANOVAs on RT interference, we found a main Task Condition effect with a Flanker effect in the joint task only, in a similar way to the classical Flanker effect found in the control task. Thus, in the joint condition, participants represented the actions of their co-actor in addition to their own actions, as if they had "two response buttons," as in the standard version of the task (Atmaca et al., 2011; Sebanz et al., 2003).

However, the action co-representation explanation does not completely account for the present findings, because in all ANOVAs the Task Condition factor failed to interact with any other factor. Thus, the results could be interpreted considering alternative explanations for the joint action effect. Indeed, the joint Flanker effect pattern found in PD patients could be discussed within the referential coding account (Dolk et al., 2011, 2013, 2014a, b), suggesting that PD patients, depending on cognitive AT scores, may be impaired in action representation, and this impairment could be related to executive function, which may, in turn, be associated with the cognitive aspect of ToM. For example, Dolk et al. (2012) recently found that structural variations in cortical gray matter volume of the medial frontal cortex (MFC) were related to individual performance differences in a joint Simon task, implying the role of the MFC in maintaining the coding of one's own and the other co-actor's action. This is in line with the findings reported by Humphreys and Bedford (2011) in frontal patients. According to the referential coding account, a joint action task requires the coding of self-own action (I-go) and other-own action (You-go), especially in a turn-taking response as in the present study (Dolk et al., 2011, 2013; Hommel, 2009, 2011; Hommel et al., 2001 Liepelt et al., 2011, 2013; Prinz, 2015; Sellaro et al., 2015; Stenzel \& Liepelt, 2016). In other words, the joint action task induces a response-selection conflict between self-own action and other-own action when a target is presented. Thus, Dolk et al., (2012) advanced the idea that the MFC was involved in a more cognitive process of action/conflict monitoring (Ridderinkhof et al., 2004). Taking into account the association between executive impairment and cognitive ToM deficit in PD (Bodden et al., 2010a, b; Costa et al., 2013; Mengelberg \& Siegert, 2003; Monetta et al., 2009; Péron et al., 2009; Roca et al., 2010; Santangelo et al., 2012), it is possible to speculate that the interference effect pattern found in our patients reflected the ability (for patients with high scores) or the difficulty (for patients with low scores) of action/control monitoring in addition to the control of conflicting responses induced by flankers. In line with this speculative interpretation, the lack of significant interference differences between joint and individual tasks in HCs could reflect how the (preserved) fronto-striatal circuities could play an important role in associating executive function and cognitive ToM.

Nevertheless, the different performances in the joint and individual Flanker task could also be explained according to the attentional-focus account (Dittrich et al., 2017; Doneva \& Cole, 2014; Fabbri et al., 2017, 2018; Porcu et al., 2016; Shteynberg, 2015). Conversely from PCC/TPJ patients, the frontal patients, who failed in the ToM task, had difficulty involving enough processing resources to code both their own action and the actions of the co-actor. Thus, the joint Flanker effect could be caused by less selective attention in the joint condition due to the presence of another person, who needs to be monitored. The different modulation of the cognitive ToM in PD patients could reflect a different impairment of cognitive resources: PD patients with high scores in the AT test had difficulty focusing on target stimuli due to the presence of a co-actor who attracted their attention while PD patients with low scores had a similar performance in both conditions, probably due to their impairment in cognitive ToM (i.e., "ignoring" the presence of another person in the joint task as if it were an individual task). Observing Figure 1a, this 
reasoning could be applied to discuss a "higher" interference effect for HCs with high AT scores in the joint condition due to more cognitive resources being consumed (Dolk et al., 2014a; Dittrich et al., 2017). It is worth noting that with our experimental setting (i.e., participants were not partitioned; they could see their own co-actor), it was difficult to differentiate between the referential coding and attentional-focusing accounts, which both postulated that "attention-grabbing events," such as co-actors or Japanese waving cats induced joint Flanker effects. Future studies are needed to investigate the mechanisms underlying the joint and individual Flanker effects in more detail.

When individuals were categorized by a median value in the EAT test, our results showed a joint Flanker effect in HCs with higher scores and in PD patients with lower scores. A possible interpretation could be that the mentalising ability is based on a dedicated, domain-specific, and modular cognitive mechanism (Fodor, 1992; Leslie \& Thaiss, 1992; Scholl \& Leslie, 1999). Considering that the Flanker task (Eriksen \& Eriksen, 1974) is a cognitive task in both the joint and individual conditions (Cohen \& Shoup, 1997), the finding that PD patients with lower scores of affective ToM exhibited a joint Flanker effect could be related to the nature of the task (detecting target letters) while the relationship between the affective subcomponent of ToM and joint action might be more evident if tasks are administered in which go/no-go signals are determined by the ability to read the eyes, faces, or pictures in which a sentiment or emotion is inferred. In line with this assumption, Sebanz et al. (2005) found a similar joint Simon effect in both individuals with autism and healthy controls. The authors discussed the similarities between autistic and control individuals, suggesting that individuals with autism could have lower-level processing of social information, even if these individuals may have specific deficits in the attribution of representational states to others. It also has been found that PD patients were mainly impaired in neuropsychological measures associated with the dorsolateral prefrontal cortex rather than the anterior cingulate cortex or orbitofrontal cortex (Zgaljardic et al., 2006). Affective ToM is thought to be mediated predominantly by the orbital fronto-striatal circuit while cognitive ToM additionally involves the dorsolateral frontostriatal circuits (Bodden et al., 2010a, b; Poletti et al., 2011). In addition, in the early stages of the disease, dopamine depletion, which causes the impairments of attention and of executive functions, is more serious in the dorsolateral fronto-striatal circuit ,while the orbital fronto-striatal circuit is almost preserved (and is affected with the progression of PD; e.g., Poletti et al., 2011). Considering that we recruited patients in the early stages of PD, the joint interference effect for patients with a "problem" in affective ToM could be explained by the spatiotemporal difference in dopamine depletion at the striatal level. Taking this into account, it is possible to understand a kind of "dissociation" between PD patients with lower scores for EAT (affective) ToM tests, who show a joint Flanker effect, and those who have low scores for AT (cognitive), who do not show this effect. Possible support for this type of dissociation derives from the association between affective ToM and frontal behavioural disturbances, in particular, those with apathy, indirectly confirming the involvement of orbitofrontal-limbic circuits (Santangelo et al., 2012). Alternatively, this finding could be due to the high sensitivity (and low specificity) of the EAT test. Indeed, all PD patients and HC individuals committed at least one error in this task and thus they were classified as impaired in affective ToM. Thus, it was not surprising that in the regression model the RT interference effect in the joint condition was also predicted by lower scores in the EAT test. Future studies are needed to investigate the differential contribution of the cognitive and affective components of ToM in action control, especially in PD patients.

However, we must be cautious when interpreting the results of the present study and making conclusions about the precise nature of the relationship between ToM, with its subcomponents, and joint action, since our PD patients exhibited considerable inter-individual differences, as shown by a large variability in the RT interference effect. Indeed, it has been observed that inter-individual differences among PD patients could account for mixed results found in the Flanker interference effect (Cagigas et al., 2007; Falkenstein et al., 2006; Lee et al., 1999). For example, Wylie et al. (2009) found a larger Flanker interference effect in PD patients than in HCs, but within the PD group this effect was quite variable, with some patients being more susceptible to incongruent flankers. In connection with this point, the fact that we chose to allow participants a comparatively long time to respond to stimuli, thus introducing noise to the RT distribution, may have limited our data. In addition, we arbitrarily decided to categorize individuals on the basis of their scores in AT and EAT tests, according to the median distribution of these scores within each group. Thus, we recognize that this categorization could have affected the assessment of the influence of cognitive and affective ToM on joint action. Although we found converging results when adopting categorical and continuous analyses, our regression model in the joint condition explained $12 \%$ of the variance, probably because PD patients exhibited a larger variability in RTs. Thus, further studies are needed to clarify how deficits in ToM can disrupt sensibility in joint action in patients with different lesions and/or neuropathological alterations.

Finally, in the present study we decided to use an Eriksen Flanker (joint) task instead of using a Simon (joint) task. Even if both tasks incorporate response conflict and they have been repeatedly used for the study of conflicts, the Flanker effect reflects stimulus conflict (i.e., incongruence between the flankers and the central target) and response conflict (i.e., incongruence between the response signalled by the flankers and the response signalled by the target) (Wendt, Heldmann, 
Münte, \& Kluwe, 2007), while the Simon effect relies on response conflict only (Hommel, 2011). As noted by Prinz (2015), in the Simon effect there is a spatial interference which arises from physical features whose coding requires the discrimination between two spatial stimuli and lateralized response keys. In contrast, in the Eriksen flanker task, there is a semantic interference relying on arbitrary categorical assignments and this effect arises from short-lived assignments between stimulus and response. In addition, different frontal and parietal cortical regions are involved in the attentional control and response selection in both Eriksen flanker and Simon tasks (see Olk, Peschke, \& Hilgetag, 2015, for a review), in line with the findings that the individual differences in cognitive control in Eriksen flanker and Simon tasks are taskspecific rather than a representation of a domain-general control mechanism (Keye, Wilhelm, Oberauer, van Revenzwaaij, 2009). Consequently, it is not surprising that Dittrich et al. (2017) found that the underlying process of joint Simon and joint Flanker effects differed. In fact, a joint Simon effect has been observed when participants perform the task with another co-actor (but this effect disappears when the task is performed individually) due to the spatial location of the coactor (Prinz, 2015), while the joint Eriksen flanker effect is greater in the joint than in the individual condition due to the assignment between go (I-go) and compatible trials, and no-go (You-go) and incompatible trials (Atmaca et al., 2011; Dolk et al., 2013). Moreover, the joint Flanker effect disappears with the introduction of a panel separating actor and co-actor (whereas the joint Simon effect remains similar with or without the partition panel; Dittrich et al., 2017). All these aspects could have implications regarding previous studies related to joint action and may also limit the interpretations of the current findings, especially considering that we did not find any differences between joint and individual performance for HCs. However, in the present study we defined the interference Flanker effect as the difference between compatible and incompatible trials (Prinz, 2015) to obtain data comparable with those observed with the joint Simon effect (i.e., the difference between congruent and incongruent trials). Using this procedure, in PD patients and HCs, independently of AT and EAT scores, we reported a Flanker interference in the joint task only, in a similar way to that reported in joint Simon studies. Furthermore, our behavioural data obtained using a go/no-go joint and individual Eriksen Flanker task could be in line with a recent study by Zmigrod, Zmigrod, and Hommel (2016) who induced a transcranial direct current stimulation (tDCS) over the right dorsolateral prefrontal cortex in healthy participants performing both standard Eriksen flanker and Simon tasks. The authors found a larger Flanker effect after the stimulation over the right dorsolateral prefrontal cortex, whereas there was no stimulation effect on performance in the Simon task. Crucially, Zmigrod et al. (2016) presented four types of stimuli in their Flanker task: congruent, incongruent, neutral, and no-go trials. Thus, the present study, which employs a go/no-go joint action paradigm, and Zmigrod et al.'s study, which uses a go/no-go Flanker task, may confirm the role of the right dorsolateral prefrontal cortex in conflict situations in patients who suffer from damage of this cortical region or, more generally, in individuals with an alteration (i.e., low cognitive ToM) of this conflict resolution area (see Beeli, Casutt, Baumgartner, \& Jäncke, 2008, for the involvement of the dorsolateral prefrontal cortex in go/no-go tasks). Future studies are needed to clarify the similarities and differences between standard and joint tasks with particular reference to the experimental procedure and neuronal areas involved.

In conclusion, by using another type of interference task, the present study showed that ToM ability, and especially the cognitive mechanism, is relevant to the social Flanker paradigm. Specifically, participants with higher scores for the cognitive ToM test showed a joint Flanker effect, suggesting an association between cognitive ToM and the ability to maintain the coding of one's own and the other person's action. The role of affective ToM in joint action remains to be understood, especially in PD patients. This role could reflect either a lower level of processing of social information for patients with lower scores in the affective ToM test, or a high sensitivity of the EAT test. Future studies should clarify how ToM and social cognition are related to each other, considering that individuals with reduced ToM abilities might have difficulties in successfully interacting with others, thus impacting their social activities and interpersonal satisfaction negatively. Specifically, an interesting line of future research should specify the functional and structural role of the frontal area in the relationship between cognitive ToM and joint action, given that, for example, in PD patients a deficit in the cognitive aspect of ToM might have a more negative impact on quality of life compared with the affective component (Santangelo et al., 2012).

\section{References}

American Psychiatric Association (1994). Diagnostic and statistical manual of mental disorders, $4^{\text {th }}$ ed. DSM-IV. Washington, DC: American Psychiatry Association.

Aron, A.R., \& Poldrack, R.A. (2006). Cortical and subcortical contributions to stop signal response inhibition: Role of the subthalamic nucleus. Journal of Neuroscience, 26, 2424-2433, https://doi.org/ 10.1523/JNEUROSCI.4682-05.2006.

Atmaca, S., Sebanz, N., \& Knoblich, G. (2011). The joint flanker effect: sharing tasks with real and imagined co-actors. Experimental Brain Research, 211, 371-385, https://doi.org/ 10.1007/s00221-011-2709-9.

Baron-Cohen, S., Leslie, A., \& Frith, U. (1985). Does the autistic child have a "theory of mind"? Cognition, 21, 37-46. https://doi.org/10. 1016/0010-0277(85)90022-8. 
Beeli, G., Casutt, G., Baumgartner, T., Jäncke, L. (2008). Modulating presence and impulsiveness by external stimulation of the brain. Behavioral and Brain Functions, 4, 33-37. https://doi.org/10.1189/ 1744-9081-4-33.

Bodden, M.E., Dodel, R., \& Kalbe, E. (2010a). Theory of mind in Parkinson's disease and related basal ganglia disorders: A systematic review. Movement Disorders, 25, 13-27. https://doi.org/10.1002/ mds. 22818

Bodden, M.E., Mollenhauer, B., Trenkwalder, C., Cabanel, N., Eggert, K.M., Unger, M.M., Oertel, W.H., Kessler, S., Dodel, R., \& Kalbe, E. (2010b). Affective and cognitive theory of mind in patients with Parkinson's disease. Parkinsonism and Related Disorders, 16, 466470. https://doi.org/10.1016/j.parkreldis.2010.04.014.

Botvinick, M.M., Braver, T.S., Carter, C.S., \& Cohen, J.D. (2001). Conflict monitoring and cognitive control. Psychological Review, 108, 624-652, https://doi.org/10.1037//0033-295X.108.3.624.

Cagigas, X.E., Filoteo, J.V., Stricker, J.L., Rilling, L.M., \& Friedrich, F.J. (2007). Flanker compatibility effects in patients with Parkinson's disease: Impact of target onset delay and trial-by-trial stimulus variation. Brain and Cognition, 63, 247-259, https://doi.org/10.1016/j. bandc.2006.09.002.

Cohen, A., \& Shoup, R. (1997). Perceptual dimensional constraints in response selection processes. Cognitive Psychology, 32, 128-181, https://doi.org/10.1006/cogp.1197.0648.

Costa, A., Peppe, A., Martini, M., Coletta, K., Oliveri, M., Caltagirone, C., \& Carlesimo G.A. (2013). Parkinsonia patients with deficits in the dysexecutive spectrum are impaired on theory of mind tasks. Behavioural Neurology, 27, 523-533. https://doi.org/10.3233/ BEN-129018.

De Jong, R., Liang, C.-C., \& Lauber, E. (1994). Conditional and unconditional automaticity: A dual-process model of effects of spatial stimulus-response correspondence. Journal of Experimental Psychology: Human Perception and Performance, 20, 731-750, https://doi.org/10.1037/0096-1523.20.4.731.

Dittrich, K., Bossert M.-L., Rothe-Wulf, A., \& Klauer, K.C. (2017). The joint flanker effect and the joint Simon effect: On the comparability of processes underlying joint compatibility effects. The Quarterly Journal of Experimental Psychology, 70, 1808-1823, https://doi.org/ 10.1080/17470218.2016.1207690

Dittrich, K., Dolk, T., Rothe-Wulf, A., Klauer, K.C., \& Prinz, W. (2013). Keys and seats: Spatial response coding underlying the joint spatial compatibility effect. Attention, Perception, \& Psychophysics, 75, 1725-1736, https://doi.org/10.3758/s13414-013-0524-z.

Dittrich, K., Rothe, A., \& Klauer, K.C. (2012). Increased spatial salience in the social Simon task: A response-coding account of spatial compatibility effects. Attention Perception \& Psychophysics, 74, 911929, https://doi.org/10.3758/s13414-012-0304-1.

Dolk, T., Hommel, B., Colzato, L.S., Schütz-Bosbach, S., Prinz, W., \& Liepelt, R. (2011). How "social" is the social Simon effect? Frontiers in Psychology, 2, 84, https://doi.org/10.3389/fpsyg.2011. 00084.

Dolk, T., Hommel, B., Colzato, L.S., Schütz-Bosbach, S., Prinz, W., \& Liepelt, R. (2014b). The joint Simon effect: a review and theoretical integration. Frontiers in Psychology, 5, 974, https://doi.org/10.3389/ fpsyg.2014.00974.

Dolk, T., Hommel, B., Prinz, W., \& Liepelt (2014a). The joint flanker effect: Less social than previously thought. Psychonomic Bulletin \& Review, 21, 1224-1230, https://doi. org/10.3758/s13423-014-0583-8.

Dolk, T., Hommel, B., Prinz, W., \& Liepelt, R. (2013). The (not so) social Simon effect: A referential coding account. Journal of Experimental Psychology: Human Perception \& Performance, 39, 1248-1260, https://doi.org/10.1037/a0031031.

Dolk, T., Liepelt, R., Villringer, A., Prinz, W., \& Ragert, P. (2012). Morphometric gray matter differences of the medial frontal cortex influence the social Simon effect. NeuroImage, 61, 1249-1254. https://doi.org/10.1016/j.neuroimage.2012.03.061.

Doneva, S.P., \& Cole, G.G. (2014). The role of attention in a joint-action effect. PloS ONE, 9, e91336, https://doi.org/10.1371/journal.pone. 0091336.

Durston, S., Davidson, M.C., Thomas, K.M., Worden, M.S., Tottenham, N., Martinez, A., \& Casey, B.J. (2003). Parametric manipulation of conflict and response competition using rapid mixed-trial event-related fMRI. NeuroImage, 20, 2135-2141, https://doi.org/10.1016/j. neuroimage.2003.08.004.

Dutilh, G., Vanderkerckhove, J., Forstmann, B.U., Keuleers, E., Brysbaert, M. \& Wagenmakers, E.-J. (2012). Testing theories of post-error slowing. Attention, Perception, \& Psychophysics, 74, 454-465. https://doi.org/10.3758/s13414-011-0243-2.

Egner, T. (2008). Multiple conflict-driven control mechanisms in the human brain. Trends in Cognitive Sciences, 12, 374-380, https:// doi.org/10.1016/j.tics.2008.07.001.

Emre, M., Aarsland, D., Brown, R., Burn, D.J., Duyckaerts, C., Mizuno, Y., et al. (2007). Clinical diagnosis criteria for dementia associated with Parkinson's disease. Movement Disorders, 22, 1689-1707, https://doi.org/10.1002/mds.21507.

Eriksen, B.A., \& Eriksen, C.W. (1974). Effects of noise letters upon the identification of a target letter in a nonsearch task. Perception \& Psychophysics, 16, 143-149. https://doi.org/10.3758/BF03203267.

Eriksen, C.W., \& Schultz, D.W. (1979). Information processing in visual search: a continuous flow conception and experimental results. Perception \& Psychophysics, 25, 249-263. https://doi.org/10.3758/ BF03198804.

Fabbri, M., Frisoni, M., Martoni, M., Tonetti, L., \& Natale, V. (2017). Synchrony effect on joint attention. Experimental Brain Research, 235, 2449-2462, https://doi.org/10.1007/s00221-017-4984-6.

Fabbri, M., Frisoni, M., Martoni, M., Tonetti, L., \& Natale, V. (2018). Influence of time-of-day on joint Navon effect. Cognitive Processing, 19, 27-40, https://doi.org/10.1007/s10339-017-0849-y.

Falkenstein, M., Willemssen, R., Hohnsbein, J., \& Hielscher, H. (2006). Effects of stimulus-response compatibility in Parkinson's disease: A psychophysiological analysis. Journal of Neural Trasmission, 113, 1449-1462, https://doi.org/10.1007/s00702-005-0430-1.

Fodor, J.A. (1992). A theory of the child's theory of mind. Cognition, 44, 283-296, https://doi.org/10.1016/0010-0277(92)90004-2.

Folstein, M., Folstein, S.E., \& McHugh, P.R. (1975). The Mini-Mental State: a practical method for grading the cognitive state of patients for the clinicians. Journal of Psychiatry Research, 12, 189-198, https://doi.org/10.1016/0022-3956(75)90026-6.

Freedman, M., \& Stuss, D.T. (2011). Theory of Mind in Parkinson's disease. Journal of the Neurological Sciences, 310, 225-227. https://doi.org/10.1016/j.ins.2011.06.004.

Frith, C.D., \& Frith, U. (1999). Interacting minds - a biological basis. Science, 286, 1692-1695. https://doi.org/10.1126/science.286.5445. 1692.

Gibb, W.R., \& Lees, A.J. (1988). The relevance of the Lewy body in the pathogenesis of idiopathic Parkinson's disease. Journal of Neurology, Neurosurgery and Psychiatry, 51, 745-752.

Goldman, J.G., \& Litvan, I. (2011). Mild cognitive impairment in Parkinson's disease. Minerva Medica, 102, 441-459.

Guagnano, D., Rusconi, E., \& Umiltà, C.A. (2010). Sharing a task or sharing space? On the effect of the confederate in action coding in a detection task. Cognition, 114, 348-355, https://doi.org/10.1016/j. cognition.2009.10.008.

Hommel, B. (2009). Action control according to TEC (theory of event coding). Psychological Research, 73, 512-526, https://doi.org/10. 1007/s00426-009-0234-2.

Hommel, B. (2011). The Simon effect as tool and heuristic. Acta Psychologica, 136, 189-202, https://doi.org/10.1016/j.actpsy.2010. 04.011. 
Hommel, B., Colzato, L.S., \& van den Wildenberg, W.P.M. (2009). How social are task representations? Psychological Science, 20, 794-798, https://doi.org/10.1111/j.1467-9280.2009.02367.x.

Hommel, B., Müsseler, J., Aschersleben, G., \& Prinz, W. (2001). The Theory of Event Coding (TEC): A framework for perception and action planning. Behavioral and Brain Sciences, 24, 849-878, https://doi.org/10.1017/S0140525X01000103.

Hübner, R., Steinhauser, M., \& Lehle, C. (2010). A dual-stage two-phase model of selective attention. Psychological Review, 117, 759-784. https://doi.org/10.1037/a0019471

Humphreys, G.W., \& Bedford, J. (2011). The relations between joint action and theory of mind: a neuropsychological analysis. Experimental Brain Research, 211, 357-369, https://doi.org/10. 1007/soo221-011-2643-x.

Kalbe, E., Schlegel, M., Sack, A.T., Nowak, D.A., Dafotakis, M., Bangard, C.,Brand, M., Shamay-Tsoory, S., Onur, O.A., \& Kessler, J. (2010). Dissociating cognitive from affective theory of mind: A TMS study. Cortex, 46, 769-780, https://doi.org/10.1016/j. cortex.2009.07.010.

Kawamura, M., \& Koyama, S. (2007). Social cognitive impairment in Parkinson's disease. Journal of Neurology, 254, IV/49-IV/53. https://doi.org/10.1007/s00415-007-4008-8.

Keye, D., Wilhelm, O., Oberauer, K., \& van Ravenzwaaij, D. (2009). Individual differences in conflict-monitoring: testing means and covariance hypothesis about the Simon and the Eriksen Flanker task. Psychological Research, 73, 762-776. https://doi.org/10.1007/ s00426-008-0188-9.

Klempova, B., \& Liepelt, R. (2015). Do you really represent my task? Sequential adaption effects to unexpected events support referential coding for joint Simon effect. Journal of Psychological Research, 80, 449-463, https://doi.org/10.1007/s00426-015-0664-y.

Kobayashi, M., Glover, G.H., \& Temple, E. (2007). Children's and adults' neural bases of verbal and nonverbal "theory of mind". Neuropsychologia, 45, 1522-1532, https://doi.org/10.1016/j. neuropsychologia.2006.11.017.

Kornblum, S., Hasbroucq, T., \& Osman, A. (1990). Dimensional overlap: Cognitive basis for stimulus-response compatibility - A model and taxonomy. Psychological Review, 97, 253-270, https://doi.org/10. 1037/0033-295X.97.2.253

Kornblum, S., \& Lee, J.W. (1995). Stimulus-response compatibility with relevant and irrelevant stimulus dimensions that do and do not overlap with the response. Journal of Experimental Psychology: Human Perception and Performance, 21, 855-875, https://doi.org/10.1037/ 0096-1523.21.4.855.

Lakens, D. (2013). Calculating and reporting effect sizes to facilitate cumulative science: a pratical primer for t-tests and ANOVAs. Frontiers in Psychology, 4, 863. https://doi.org/10.3389/fpsyg. 2013.00863.

Lavie, N., Hirst, A., De Fockert, J.W., \& Viding, E. (2004). Load theory of selective attention and cognitive control. Journal of Experimental Psychology: General, 133, 339-354. https://doi.org/10.1037/00963445.133.3.339

Lee, S.S., Wild, K., Hollnagel, C., \& Grafman, J. (1999). Selective visual attention in patients with frontal lobe lesions or Parkinson's disease. Neuropsychologia, 37, 595-604, https://doi.org/10.1016/S00283932(98)00081-5.

Leslie, A.M., \& Thaiss, L. (1992). Domain specificity in conceptual development: Neuropsychological evidence from autism. Cognition, 43, 225-251, https://doi.org/10.1016/0010-0277(92)90013-8.

Liepelt, R., Wenke, D., \& Fischer, R. (2013). Effects of features integration in a hands-crossed version of the Social Simon paradigm. Psychological Research, 77, 240-248, https://doi.org/10.1007/ s00426-012-0425-0.

Liepelt, R., Wenke, D., Fischer, R., \& Prinz, W. (2011). Trial-to-trial sequential dependencies in a social and non-social Simon task.
Psychological Research, 75, 366-375, https://doi.org/10.1007/ s00426-010-0314-3.

Measso, G., Cavarzeran, F., Zappalà, G., Lebowitz, B.D., Crook, T.H., Pirozzolo, F.J., Amaducci, L.A., Massari, D., \& Grigoletto, F. (1993). The Mini-Mental State Examination: normative study of an Italian random sample. Developmental Neuropsychology, 9, 7785, https://doi.org/10.1080/87565649109540545.

Memelink, J., \& Hommel, B. (2013). Intentional weighting: A basic principle in cognitive control. Psychological Research, 77, 249259, https://doi.org/10.1007/s00426-012-0435-y.

Mengelberg, A., \& Siegert, R.J. (2003). Is Theory of Mind impaired in Parkinson's disease? Cognitive Neuropsychiatry, 8, 191-209. https:// doi.org/10.1080/13546800244000292.

Miller, I.N., \& Cronin-Golomb, A. (2010). Gender differences in Parkinson's disease: a clinical characteristics and cognition. Movement Disorders, 25, 2695-2703, https://doi.org/10.1002/mds. 23388.

Monetta, L., Grindrod, C.M., \& Pell, M.D. (2009). Irony comprehension and theory of mind deficits in patients with Parkinson's disease. Cortex, 45, 972-981. https://doi.org/10.1016/j.cortex.2009.02.021.ù

Müller, B.C.N., Brass, M., Kühn, S., Tsai, C.-C., Nieuwboer, W., Dijksterhuis, A., \& van Baaren, R.B. (2011a). When Pinocchio acts like a human, a wooden hand becomes embodied. Action corepresentation for non-biological agents. Neuropsychologia, 49 , 1373-1377, https://doi.org/10.1016/j.neuropsychologia.2011.01. 022.

Müller, B.C.N., Kühn, S., van Baaren, R.B., Dotsch, R., Brass, M., \& Dijksterhuis, A.P. (2011b). Perspective taking eliminates differences in co-represntation of out-group members' action. Experimental Brain Research, 211, 423-428, https://doi.org/10.1007/s00221011-2654-7.

Mussi, D.R., Marino, B.F.M., \& Riggio, L. (2015). The influence of social and nonsocial variables on the Simon effect. Experimental Psychology, 62, 215-231, https://doi.org/10.1027/1618-3169/ a000292.

Obeso, J.A., Rodriguez-Oroz, M.C., Rodriguez, M., Lanciego, J.L., Artieda, J., Gonzalo, N., \& Olanow, C.W. (2000). Pathophysiology of the basal ganglia in Parkinson's disease. Trends in Neuroscience, 23, S8-S19. https://doi.org/10.1016/ S1471-1931(00)00028-8.

Olk, B., Peschke, C., \& Hilgetag, C.C. (2015). Attention and control of manual responses in cognitive conflict: findings from TMS perturbation studies. Neuropsychologia, 74, 7-20. https://doi.org/10.1016/ j.neuropsychologia.2015.02.008.

Owen, A.M. (2004). Cognitive dysfunction in Parkinson's disease: The role of frontostriatal circuity. Neuroscientist, 10, 527-537. https:// doi.org/10.1177/1073858404266776.

Péron, J., Vicente, S., Leray, E., Drapier, S., Drapier, D., Cohen, R., Biseul, I., Rouaud, T., Le Jeune, F., Sauleau, P., \& Vérin, M. (2009). Are dopaminergic pathways involved in theory of mind? A study in Parkinson's disease. Neuropsychologia, 4, 406-414, https://doi.org/10.1016/j.neuropsychologia.2008.09.008.

Peterburs, J., Liepelt, R., Voegler, R., Ocklenburg, S., \& Straube, T. (2017). It's not me, it's you. Differential neural processing of social and non-social nogo cues in joint action. Social Neuroscience, 12, 111, https://doi.org/10.1080/17470919.2017.1403374.

Poewe, W., Gauthier, S., Aarsland, D, Leverenz, J.B., Barone, P., Weintraub, D., Tolosa, E., Dubois, B. (2008). Diagnosis and management of Parkinson's disease. International Journal of Clinical Practice, 62, 1581-1587, https://doi.org/10.1111/j.1742-1241.2008. 01869.x.

Poletti, M., Enrici, I., Bonuccelli, U., \& Adenzato, M. (2011). Theory of mind in Parkinson's disease. Behavioural Brain Research, 219, 342 350. https://doi.org/10.1016/j.bbr.2011.01.010.

Porcu, E., Bölling, L., Lappe, M., \& Liepelt, R. (2016). Pointing out mechanisms underlying joint action. Attention, Perception, \& 
Psychophysics, 78, 972-977. https://doi.org/10.3758/s134141-0161093-8.

Praamstra, P., Plat, E.M., Meyer, A.S., \& Horstink, M.W. (1999). Motor cortex activation in Parkinson's disease: Dissociation of electrocortical and peripheral measures of response generation. Movement Disorders, 14, 790-799, https://doi.org/10.1002/15318257(199909)14:5<790:AID-MDS1011>3.0.CO;2-A.

Praamstra, P., Stegeman, D., Cools, A., \& Horstink, M. W. (1998). Reliance on external cues for movement inititation in Parkinson's disease: Evidence from movement-related potentials. Brain, 121, 167, https://doi.org/10.1093/brain/121.1.167.

Premack, D., \& Woodruff, G. (1978). Does the chimpanzee have a theory of mind? Behavioral and Brain Sciences, 1, 515-526. https://doi. org/10.1017/S0140525X00076512.

Prinz, W. (2015). Task representation in individual and joint settings. Frontiers in Human Neuroscience, 9, 268. https://doi.org/10.3389/ fnhum.2015.00268.

Prior, M., Marchi, S., \& Sartori, G. (2003). Cognizione sociale e comportamento. Uno strumento per la misurazione [Social cognition and behavior. A tool for assessment]. Padova: Upsel Domenighini Editore.

Puffe, L., Dittrich, K., \& Klauer, K.C. (2017). The influence of the Japanese waving cat on the joint spatial compatibility-effect: A preolication and extension of Dolk, Hommel, Prinz, and Liepelt (2013). PLoS ONE, 12, e0184844. https://doi.org/10.1371/journal. pone. 0184844

Ridderinkhof, K.R., van den Wildenberg, W.P.M., Segalowitz, S.J., \& Carter, C.S. (2004). Neurocognitive mechanisms of cognitive control: The role of prefrontal cortex in action selection, response inhibition, performance monitoring, and reward-based learning. Brain and Cognition, 56, 129-140, https://doi.org/10.1016/j.bandc.2004. 09.016

Roca, M., Torralva, T., Gleichgerrcht, E., Chade, A., Arevalo, G.G., Gershanik, O., \& Manes, F. (2010). Impairments in social cognition in early medicated and unmedicated Parkinson disease. Cognition and Behavioral Neurology, 23, 152-158. https://doi.org/10.1097/ WNN.0b013e3181e078de.

Saltzman, J., Strauss, E., Hunter, M., \& Archibald, S. (2000). Theory of Mind and executive functions in normal human aging and Parkinson's disease. Journal of the International Neuropsychological Society, 6, 781-788. https://doi.org/10.1017/ S1355617700677056.

Santangelo, G., Vitale, C., Trojano, L., Errico, D., Amboni, M., Barbarulo, A.M., Grossi, D., \& Barone, P. (2012). Neuropsychological correlates of theory of mind in patients with early Parkinson's disease. Movement Disorders, 27, 98-105. https://doi.org/10.1002/mds.23949.

Scholl, B.J., \& Leslie, A.M. (1999). Modularity, development, and "theory of mind". Mind and Language, 14, 131-153, https://doi. org/10.1111/1468-0017.00106

Sebanz, N., Knoblich, G., \& Prinz, W. (2003). Representing others' actions: just like one's own? Cognition, 88, B11-B21, https://doi.org/ 10.1016/S0010-0277(03)00043-X.

Sebanz, N., Knoblich, G., Stumpf, L., \& Prinz, W. (2005). Far from action-blind: representation of others' action in individuals with autism. Cognitive Neuropsychology, 22, 433-454, https://doi.org/10. 1080/02643290442000121.

Sellaro, R., Dolk, T., Colzato, L.S., Liepelt, R., \& Hommel, B. (2015). Referential coding does not rely on location features: evidence for a nonspatial joint Simon effect. Journal of Experimental Psychology: Human Perception and Performance, 41, 186-195, https://doi.org/ 10.1037/a00385.48.

Shamay-Tsoory, S.G., \& Aharon-Peretz, J. (2007). Dissociable prefrontal networks for cognitive and affective theory of mind. A lesion study. Neuropsychologia, 45, 3054-3067, https://doi.org/10.1016/j. neuropsychologia.2007.05.021.
Shamay-Tsoory, S.G., Harari, H., Aharon-Peretz, J., \& Levkovitz, Y. (2010). The role of the orbitofrontal cortex in affective theory of mind deficits in criminal offenders with psychopathic tendencies. Cortex, 46, 668-677. https://doi.org/10.1016/j.cortex.2009.04.008.

Shamay-Tsoory, S.G., Shur, S., Barcai-Goodman, L., Medlovich, S., Harari, H., \& Levkovitz, Y. (2007). Dissociation of cognitive from affective components of theory of mind in schizophrenia. Psychiatry Research, 149, 11-23, https://doi.org/10.1016/j.psychres.2005.10.018.

Shteynberg, G. (2015). Shared attention. Perspective \& Psychological Science, 10, 579-590. https://doi.org/10.1177/1745691615589104.

Simon, J.R. (1969). Reactions towards the source of stimulation. Journal of Experimental Psychology, 81, 174-176. https://doi.org/10.1037/ h0027448.

Simon, J.R. (1990). The effects of an irrelevant directional cue on human information processing. Advances in Psychology, 65, 31-86, https:// doi.org/10.1016/S0166-4115(08)61218-2.

Sommer, M., Dohnel, K., Sodian, B., Meinhardt, J., Thoermer, C., \& Hajak, G. (2007). Neural correlates of true and false belief reasoning. NeuroImage, 35, 1378-1384, https://doi.org/10.1016/j. neuroimage.2007.01.042.

Spinnler, H., \& Tognoni G. (1987). Standardizzazione e taratura italiana di una batteria di test neuropsicologici [Italian standardization and classification of Neuropsychological tests. The Italian Group on the Neuropsychological Study of Aging]. Italian Journal of Neurological Sciences, 8 (Suppl. 6), 1-120.

Stenzel, A., \& Liepelt, R. (2016). Joint Simon effects for non-human coactors. Attention Perception \& Psychophysics, 78, 143-158, https:// doi.org/10.3758/s13414-015-0994-2.

van der Weiden, A., Aarts, H., Prikken, M., \& van Haren, N.E.M. (2016). Individual differences in action co-representation: not personal distress or subclinical psychotic experiences but sex composition modulates joint action performance. Experimental Brain Research, 234, 499-510, https://doi.org/10.1007/s00221-015-4475-6.

Wen, T., \& Hsieh, S. (2015). Neuroimaging of the joint Simon effect with believed biological and non-biological co-actors. Frontiers in Human Neuroscience, 9, 483, https://doi.org/10.3389/fnhum.2015. 00483.

Wendt, M., Heldmann, M., Münte, T.F., \& Kluwe, R.H. (2007). Disentangling sequential effects of stimulus- and response-related conflict and stimulus-response repetition using brain potentials. Journal of Cognitive Neuroscience, 19, 1104-1112. https://doi.org/ 10.1162/jocn.2007.19.7.1104.

Williams-Gray, C.H., Evans, J.R., Goris, A., Foltynie, T., Ban, M., Robbins, T.W., Brayne, C., Kolachana, B.S., Weinberger, D.R., Sawcer, S.J., \& Barker, R.A. (2009). The distinct cognitive syndromes of Parkinson's disease: 5 year follow-up of the CamPaIGN cohort. Brain, 132, 2958-2969. https://doi.org/10.1093/brain/ awp245.

Wylie, S.A., Stout, J.C., \& Bashore, T.R. (2005). Activation of conflicting responses in Parkinson's disease: Evidence for degrading and facilitating effects on response time. Neuropsychologia, 43, 1033-1043, https://doi.org/10.1016/j.neuropsychologia.2004.10.008.

Wylie, S.A., van den Wildenberg, W.P.M., Ridderinkhof, K.R., Bashore, T.R., Powell, V.D., Manning, C.A., \& Wooten, G.F. (2009). The effect of Parkinson's disease on interference control during action selection. Neuropsychologia, 47, 145-157, https://doi.org/10.1016/j. neuropsychologia.2008.08.001.

Yu, R.-L., \& Wu, R.-M. (2013). Social brain dysfunctions in patients with Parkinson's disease: a review of theory of mind studies. Translational Neurodegeneration, 2, 7. https://doi.org/10.1189/ 2047-9158-2-7.

Zgaljardic, D.J., Borod, J.C., Foldi, N.S., \& Mattis, P. (2003). A review of the cognitive and behavioral sequelae of Parkinson's disease: Relationship to frontostriatal circuitry. Cognitive and Behavioral Neurology, 16, 193-210. https://doi.org/10.1097/00146965200312000-00001. 
Zgaljardic, D.J., Borod, J.C., Foldi, N.S., Mattis, P.J., Gordon, M.F., Feigin, A., \& Eidelberg, D. (2006). An examination of executive dysfunction associated with frontostriatal circuitry in Parkinson's disease. Journal of Clinical and Experimental Neuropsychology, 28, 1127-1144. https://doi.org/10.1080/13803390500246910.
Zmigrod, S., Zmigrod, L., \& Hommel, B. (2016). Transcranial direct current stimulation (tDCS) over the right dorsolateral prefrontal cortex affects stimulus conflict but not response conflict. Neuroscience, 322, 320-325, https://doi.org/10.1016/ j.neuroscience.2016.02.046. 